\title{
Diapycnal mixing in Gulf Stream meanders
}

\author{
A. Rodríguez-Santana, J. L. Pelegrí, P. Sangrà, and A. Marrero-Díaz \\ Departamento de Física, Facultad de Ciencias del Mar, Universidad de Las Palmas de Gran \\ Canaria, Canary Islands, Spain
}

\begin{abstract}
We use historical data [Bane et al., 1981], interpolated to isopycnic coordinates, to examine the possibility of significant diapycnal mixing within the upper thermocline layers of the Gulf Stream. The data consist of 28 air-dropped expendable bathythermograph (AXBT) sections in the northern Blake Plateau distributed in five different surveys done within 8 days. From the data we obtain a separation index between isopycnals $j=\rho \partial z / \partial \rho$, where $z$ is the depth of an isopycnal and $\rho$ is the density; the diapycnal shear $\partial v / \partial \rho$, where $v$ is the geostrophic velocity; and the gradient Richardson number Ri. Following Pelegri and Csanady [1994], we postulate that the material derivative of the density, or density tendency $w_{\rho}=D \rho / D t$, is the result of small-scale instabilities related to near-critical $R i$ values. We present the distribution of these quantities $\left(j, \partial v / \partial \rho, R i\right.$, and $\left.w_{\rho}\right)$ and the diapycnal convergence/divergence $\left(\partial w_{\rho} / \partial \rho\right)$ over isopycnals and on sections normal to the coast. The results show the passage of steep meanders being related to anomalously low $j$ values (strong density gradients) within the upper thermocline layers and the cyclonic filaments of the stream. The statically stable upper thermocline layers, however, are concurrent with large diapycnal shear and turn out to be dynamically unstable, characterized by low $R i$ and high-density tendencies and diapycnal convergence/divergence. The errors involved in calculating the dependent variables from AXBT data are assessed using both an error propagation approach and a Monte Carlo error simulation. These errors, although significant, are not large enough to modify the observed patterns substantially.
\end{abstract}

\section{Introduction}

It is surprising that despite Stommels [1965, p. 116] early proposal of localized intense diapycnal mixing within the upper thermocline layers of the Gulf Stream, until now there have been very few studies of this phenomenon. This is perhaps even more striking if we consider the structural similarities between the Gulf Stream and other oceanic and atmospheric jets, where shearinduced turbulence is substantial. Examples of these are the equatorial undercurrent [Peters et al., 1988], the coastal upwelling jet [Kundu and Beardsley, 1991; Pelegri and Richman, 1993, 1994], and the polar jet stream [Keyser and Shapiro, 1986].

One of the few studies on diapycnal mixing within the Gulf Stream is due to Gregg and Sanford [1980], who calculated gradient Richardson numbers $R i$ within the Gulf Stream, using $50 \mathrm{~m}$ averaged temperature and velocity profiles. They obtained values as low as $R i=2$ and suggested that shear mixing was possible. However, because of the existence of step-like density structures and high Cox numbers, their conclusion was that this mechanism is probably not as important as dou-

Copyright 1999 by the American Geophysical Union.

Paper number 1999JC900219.

0148-0227/99/1999JC900219\$09.00 ble diffusion. Other studies concentrated on diapycnal mixing between shelf/slope waters and Gulf Stream waters [Ruddick and Bennett, 1985; Lillibridge et al., 1990; Churchill et al., 1993] and obtained estimates for $R i$ near the north wall edge of the Gulf Stream that suggested the relatively little importance of shear mixing as compared with double diffusion.

Two relatively recent findings point at the need to revisit the possibility of shear-induced mixing within the upper thermocline layers of the Gulf Stream. The first one is the recognition that relatively little smoothing of the density and velocity data is very important for the calculations of $R i$ in well-stratified regions. Miller and Evans [1985] and Padman and Jones [1985] have shown that the vertical density and velocity gradients are very sensitive to the chosen vertical scales and that smoothing over distances as small as $10 \mathrm{~m}$ causes a considerable increase in the estimates for $R i$. The second one is our better understanding of two instability mechanisms that produce series of constant density steps as a result of the dependence of density flux with $R i$. These are the Phillips-Posmentier mechanism [Phillips, 1972; Posmentier, 1977; Ruddick et al., 1989; Park et al., 1994] and a mechanism proposed by Pelegri and Sangrà [1998] where shear-induced turbulence lasts during some characteristic finite time.

Miller and Evans [1985] and Schmitt et al. [1986] have studied the possibility of shear-induced mixing in cold- 
and warm-core rings formed by Gulf Stream meanders, respectively. Schmitt et al. [1986] used highly smoothed vertical shear (over $300 \mathrm{~m}$ ) to calculate $R i$ and, even so, obtained values close to 1 . They recognized that this smoothing leads to increased $R i$ values and suggested that shear-driven turbulence may be a strong mixing mechanism. Miller and Evans [1985] did a careful analysis on the effects of smoothing on $R i$ and found that smoothing over increasing vertical distances (ranging between 1 and $10 \mathrm{~m}$ ) can cause $R i$ to go from subcritical to supercritical. They chose a smoothing interval of $2 \mathrm{~m}$ as a compromise between retaining high shear values and reducing contamination from small-scale turbulence. With this smoothing they then calculated mean $R i$ values over layers $\sim 100 \mathrm{~m}$ thick, within a cold-dome Gulf Stream ring, and obtained values usually below 1 and often below 0.25 . One corollary from the existence of low $R i$ values in Gulf Stream rings, which have their origin on meanders pinching off the Gulf Stream, is the possibility of similarly low values in steep meanders.

Pelegri and Csanady [1991, 1994] obtained results indicating that diapycnal mixing is a likely phenomenon in the upper thermocline layers of the Gulf Stream. Pelegri and Csanady [1991] examined water and nutrient balances for several isopycnals of the Gulf Stream to conclude that water is exchanged between the upper thermocline and surface layers. Pelegri and Csanady [1994] observed good correspondence between regions of large diapycnal convergence and anomalies in both stratification and potential vorticity, as predicted from theoretical arguments. They defined an index of separation between isopycnals as $j=J \rho$, where $J=\partial z / \partial \rho$, $z$ is the depth of an isopycnal, and $\rho$ is its density, and postulated that diapycnal mixing is the consequence of anomalously low $j$ values (high stratification) produced during frontogenesis in some phase of the meanders.

More recently, Pelegri et al. [1996] have discussed several pieces of evidence on the importance of diapycnal mixing. One significant evidence is the coincidence of large diapycnal mixing with nutrient anomalies taking place within the core of a nutrient stream. They propose that this exchange, repeated in time and space, is responsible for the overall diapycnal nutrient flux from the thermocline to the surface layers observed by Pelegri and Csanady [1991] as well as for maintaining patchy productivity within the surface layers of the Gulf Stream. Lohrenz et al. [1993] have actually found episodic enhanced productivity downstream of meander crests and suggested that it may be caused by nutrient injection through shear-induced mixing.

Iselin [1950], Rossby [1951], and Newton $[1959,1961]$ early recognized the existence of structural and dynamic parallelisms between the Gulf Stream and the polar atmospheric jet stream. Newton [1978] pointed at similarities of convergence/divergence and vertical motions associated with meanders in both the Gulf Stream and the polar atmospheric jet, which have since been verified [Bower, 1989; Bower and Rossby, 1989]. Another similarity is the asymmetry between crests and troughs, with frontogenesis and increased (horizontal) cyclonic shear taking place between a crest and the subsequent trough [Palmén and Newton, 1969; Newton, 1978]. These and other analogies between the oceanic and atmospheric counterparts still require further research. Frontal zones of the polar jet stream, for example, are statically stable but experience vertical shearing instabilities (for a review, see Keyser and Shapiro [1986]), and it is plausible that this is also mirrored in the Gulf Stream.

In this paper we will analyze how and where diapycnal mixing may actually take place. Specifically, we will examine the hypothesis posed by Pelegri and Csanady [1991, 1994] that diapycnal mixing is due to episodic high diapycnal shear and associated instability taking place during frontogenetical phases of Gulf Stream meanders. In section 2 we briefly review the procedure used to calculate $R i$ and the diapycnal convergence/divergence. In section 3 we present the data set and briefly discuss how it has been treated, leaving the details of a rather exhaustive error analysis for section 4 . In section 5 we show the main results, and in section 6 we give the conclusions.

\section{Diapycnal Convergence}

To estimate the diapycnal convergence/divergence, we have essentially followed the procedure described by Pelegri and Csanady [1994]. We now briefly review the main aspects of their formulation together with some differences in the parameterization of the vertical density diffusivity.

The mean density tendency $\tilde{w}_{\rho}$, or material change of density over a long timescale, is interpreted as the result of mixing taking place over shorter timescales. Decomposing the density and velocity fields into fast (prime) and slow (tilde) motions, $\rho=\tilde{\rho}+\rho^{\prime}, u=\tilde{u}+u^{\prime}$, etc., and taking the mean over the long timescale, we get

$$
\begin{aligned}
\tilde{w}_{\rho} & \equiv \frac{D \rho}{D t} \equiv \frac{\partial \tilde{\rho}}{\partial t}+\tilde{u} \frac{\partial \tilde{\rho}}{\partial x}+\tilde{v} \frac{\partial \tilde{\rho}}{\partial y}+\tilde{w} \frac{\partial \tilde{\rho}}{\partial z} \\
& =-\nabla \cdot \tilde{\mathbf{F}} \simeq-\frac{\partial F_{z}}{\partial z}
\end{aligned}
$$

where the Reynolds density flux vector is defined as $\tilde{\mathbf{F}} \equiv\left(\tilde{F}_{x}, \tilde{F}_{y}, \tilde{F}_{z}\right) \equiv\left(\overline{u^{\prime} \rho^{\prime}}, \overline{v^{\prime} \rho^{\prime}}, \overline{w^{\prime} \rho^{\prime}}\right)$, and we have assumed incompressibility. The approximation used in (1) corresponds to the case of vertical flux convergence/divergence much larger than horizontal flux convergence/divergence, and it will be quantified later in this section.

The vertical component of the Reynolds density flux is parameterized as proportional to the vertical density gradient:

$$
F_{z}=-K_{v} \frac{\partial \tilde{\rho}}{\partial z}=-\frac{K}{\tilde{J}},
$$

where $K_{v}$ is the vertical density eddy diffusivity and $\tilde{J}=\partial \tilde{z} / \partial \tilde{\rho}$, with $\tilde{z}=z(x, y, \rho=\tilde{\rho})$. Substitution into (1) leads to (hereafter, we will always refer to the longtime mean quantities, so we drop tildes) 


$$
w_{\rho} \simeq \frac{1}{J} \frac{\partial\left(K_{v} / J\right)}{\partial \rho}=\frac{1}{J^{2}} \frac{\partial K_{v}}{\partial \rho}-\frac{K_{v}}{J^{3}} \frac{\partial J}{\partial \rho} .
$$

Assuming that mixing is the result of shear-induced unstable geostrophic events, we can parameterize $K_{v}$ as a function of the gradient Richardson number $R i$, approximated by

$$
R i=\frac{g \frac{\partial \rho}{\partial z}}{\rho\left(\frac{\partial v}{\partial z}\right)^{2}}=\frac{g J}{\rho\left(\frac{\partial v}{\partial \rho}\right)^{2}}=\frac{f^{2} j}{g\left(\frac{\partial z}{\partial x}\right)^{2}}
$$

where $g$ is the gravity acceleration, $f$ is the Coriolis parameter, $v$ is the along-stream geostrophic velocity, and $j=J \rho$ is the index of separation defined by Pelegri and Csanady [1994]. The separation index could be interpreted as the distance over which the local density gradient would have to act to produce a total density change from zero to $\rho$. This quantity has the appeal that changes in $j$ are, together with changes in total vorticity, directly responsible for changes in potential vorticity [Pelegri and Csanady, 1994, equation (33)].

In (4) we have approximated the vertical geostrophic shear by the vertical shear of the along-stream geostrophic velocity $(\partial v / \partial z)$. The second equality is the appropriate expression in isopycnic coordinates, with $\partial v / \partial \rho$ being the diapycnal shear, while the last equality has made use of the thermal wind equation in isopycnic coordinates $(\rho f \partial v / \partial \rho=g \partial z / \partial x)$. Note that the thermal wind equation allows for obtaining a geostrophic $R i$ without needing a velocity reference level. In the absence of density inversions, $J, j$, and $R i$ are negative numbers, but we will follow the usual convention of taking their absolute values.

In the above expression we actually calculate $R i$ due to geostrophic shear in Gulf Stream meanders, in agreement with the hypothesis that subcritical regions are intermittently produced during frontogenetical phases of the meanders. These regions should be reflected by the spatial distribution of the above geostrophic $R i$ and the associated mixing properties. Our geostrophic approach ignores the contribution to mixing by submesoscale features such as internal gravity waves or tides; these may be important but are not addressed here. Another difficulty with baroclinic tides is that they could produce significant cross-stream isopycnal displacements that would induce an error in our estimates of the geostrophic diapycnal shear (the importance of this error is assessed in section 4).

The choice of parameterization for $K_{v}=K_{v}(R i)$ is a difficult issue. Since the early proposal by $M u n k$ and Anderson [1948] there have been numerous variations [e.g., Pacanowski and Philander, 1981; Ueda et al., 1981; Turner, 1986; Pelegrí and Csanady, 1994] that follow Munk and Anderson's low inverse dependence with Ri. Peters et al. [1988] used simultaneous measurements of shear and microstructure in the equatorial undercurrent to obtain a two-regime $K_{v}(R i)$ dependence, with a Munk and Anderson type function for high $R i$ but with a quite different function for the $R i<0.4$ range. For these low $R i$ values they obtained a nearly catastrophic dependence, $K_{v} \sim R i^{-9}$, which is very appealing because it conforms to the theoretical condition of rapid mixing developing in subcritical conditions. Figure 1 shows the shape of the $K_{v}=K_{v}(R i)$ dependence according to Pacanowski and Philander [1981], Peters et al. [1988], and Pelegrí and Csanady [1994]; in Figure 1 we have adapted a curve to Peters et al.'s [1988] measurements (dots) for the $R i \geq 0.4$ region.

For our calculations we have chosen a two-regime parameterization for $K_{v}(R i)$, with a $M u n k$ and Anderson [1948] type formulation for the high $R i$ range and Peters et al. [1988] dependence for the low $R i$ range:

$$
K_{v}= \begin{cases}1.1 \times 10^{-8} R i^{-9.2} & R i \leq 0.33 \\ 2.6 \times 10^{-3}(1+10 R i)^{-3 / 2} & R i>0.33\end{cases}
$$

The high $R i$ range dependence has been chosen following Pelegrí and Csanady [1994], which conforms to the widely accepted $R i^{-3 / 2}$ dependence for large $R i$ [e.g., Turner, 1986]. This selection provides a relatively smooth transition between the low and high $R i$ regimes taking place at $R i=0.33$. It may be justified as a compromise between the appealing high-order dependence for low $R i$ values and Peters et al.'s [1988] recognition that their indirect method for flux determination may have significant uncertainties. In any case, as Figure 1 suggests, a change in parameterization would modify the absolute numbers of the mixing properties but not their spatial patterns.

We will now quantify the approximation in (1). Using the parameterization in (2) and a similar one for an arbitrary horizontal direction $x$, the approximation becomes

$$
\left|\frac{\partial}{\partial z}\left(K_{v} \frac{\partial \rho}{\partial z}\right)\right|>>\left|\frac{\partial}{\partial x}\left(K_{h} \frac{\partial \rho}{\partial x}\right)\right|,
$$

where $K_{h}$ is the horizontal density eddy diffusivity. Typical values of $K_{h}$ and $K_{v}$ in the upper permanent thermocline are 3 and $1.5 \times 10^{-5} \mathrm{~m}^{2} \mathrm{~s}^{-1}$, respectively [Ledwell et al., 1993]. For a density change of $1 \mathrm{~kg}$ $\mathrm{m}^{-3}$ the horizontal and vertical scales are $10^{6}$ and $10^{3}$ $\mathrm{m}$, respectively. Substitution of these numbers into (6) shows that both terms are of the same order $\left(10^{-11} \mathrm{~kg}\right.$ $\mathrm{m}^{-3} \mathrm{~s}^{-1}$ ), indicating that in the permanent thermocline the density tendency may indeed be controlled by both horizontal and vertical convergence/divergence.

The situation we are interested for Gulf Stream meanders is quite different from the previous one, essentially because of the existence of highly compressed regions that maintain a large diapycnal shear. Relation (4) above shows that under these conditions, $R i$ may be subcritical; that is, these well-stratified layers may be dynamically unstable. A typical (vertically smoothed) value for the separation index in these layers is $j \simeq 10^{5}$ $m$ (section 5), which corresponds to density and vertical scales of $0.1 \mathrm{~kg} \mathrm{~m}^{-3}$ and $10 \mathrm{~m}$, respectively. The value for $K_{v}$ in these regions corresponds to near-critical Richardson values (section 5), being $\sim 4 \times 10^{-4} \mathrm{~m}^{2} \mathrm{~s}^{-1}$ (Figure 1). With these numbers a typical value for 


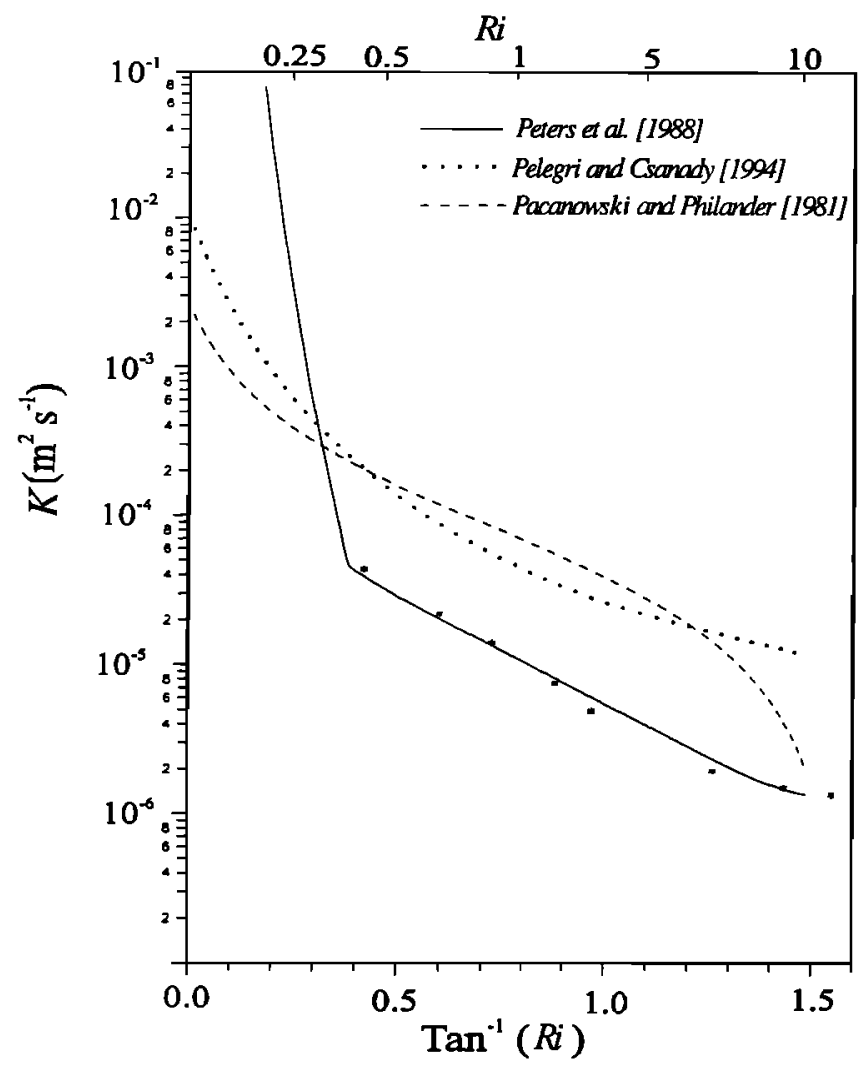

Figure 1. Vertical density eddy diffusivity $K$ as a function of the Richardson number $R i$ according to parameterizations by Pacanowski and Philander [1981], Peters et al. [1988], and Pelegrí and Csanady [1994]. The parameterization used corresponds to the Peters et al. [1988] curve for $R i \leq 0.33$ and to the Pelegrí and Csanady [1994] curve for $\bar{R} i>0.33$.

$\partial F_{z} / \partial z$ is $4 \times 10^{-7} \mathrm{~kg} \mathrm{~m}^{-3} \mathrm{~s}^{-1}$ and much larger in subcritical regions because of the large inverse dependence $K_{v} \sim R i^{-9}$.

The above number must now be compared with those associated with horizontal density convergence/divergence within the Gulf Stream. A first estimate may be obtained using Ledwell et al.'s [1993] values for $K_{h}$ (3 $\mathrm{m}^{2} \mathrm{~s}^{-1}$ ) and the horizontal density gradients associated with Gulf Stream meanders (changes of $0.6 \mathrm{~kg} \mathrm{~m}^{-3}$ over some $20 \mathrm{~km}$; see section 3 ), giving $\partial F_{x} / \partial x \simeq 4 \times 10^{-9}$ $\mathrm{kg} \mathrm{m}^{-3} \mathrm{~s}^{-1}$. A similar estimate may be obtained using the mean horizontal density gradients $\left(\sim 0.8 \mathrm{~kg} \mathrm{~m}^{-3}\right.$ over $200 \mathrm{~km}$ ) and a mean horizontal density diffusivity $\left(250 \mathrm{~m}^{2} \mathrm{~s}^{-1}\right)$ calculated from the overall distribution of scalar properties [Bower et al., 1985; Csanady and Hamılton, 1988]. With these figures we get a typical value $\partial F_{x} / \partial x \simeq 5 \times 10^{-9} \mathrm{~kg} \mathrm{~m}^{-3} \mathrm{~s}^{-1}$. Both estimates for the horizontal density convergence/divergence agree, showing that the local horizontal diffusion can sustain the large-scale diffusion implied by the steady distribution of scalar properties within the Gulf Stream. These estimates, however, are 2 orders of magnitude smaller than the vertical density convergence/divergence, which verifies the approximation employed in (1).
Substitution of (5) into (3) allows us to calculate explicitly the density tendency $w_{\rho}$ and its diapycnal convergence $\partial w_{\rho} / \partial \rho$ over a grid with density-depth data. The intensity of the density tendency reveals the degree of mass (and tracers such as nutrients) exchange between adjacent isopycnal layers, while it is the diapycnal convergence that controls the separation between isopycnals. When diapycnal convergence is dominant, the mass conservation equation reduces to [Pelegri and Csanady, 1994]

$$
\frac{D j}{D t} \simeq-\frac{\partial w_{\rho}}{\partial \rho} j
$$

This tells us that the separation between adjacent isopycnals will increase (decrease) with diapycnal convergence (divergence), i.e., with negative (positive) $\partial w_{\rho} / \partial \rho$ values (recall that $J$ is a negative quantity, although it is usual to show its absolute value).

\section{Data Analysis}

We have used a data set of sequential air-dropped expendable bathythermograph (AXBT) surveys over the Gulf Stream, provided to us by J. Bane from the University of North Carolina. It was obtained during February 1979 in the northern Blake Plateau (off the North and South Carolina coasts, north of Charleston Bump), where substantial meanders are observed to progress northward. These data have been previously used to study the generation, structure, dynamics, and energy characteristics of the meanders [Bane et al., 1981; Brooks and Bane, 1981, 1983; Hood and Bane, 1983; Chew et al., 1985; Luther and Bane, 1985].

An excellent attribute of this data set is the fast coverage (in a few hours) of a relatively large region down to almost $400 \mathrm{~m}$, during five different flights done within 8 days (February $9,11,14,15$, and 17 ). The number of AXBT sections for each flight ranges between four and seven, for a total of 28 sections and over 250 stations. Although the sections taken during different flights are not exactly at the same location, they are close enough that we have decided to call them sections $A, C, E, G$, $\mathrm{I}, \mathrm{K}$, and $\mathrm{M}$, from north to south (Figure 2).

Salinity $S$ is obtained from temperature $T$ by a recursive utilization of Bryden's [1973] algorithm for potential temperature $\theta$ and Armi and Bray's [1982] algorithm for the relationship between $S$ and $\theta$ in the northwestern Atlantic Ocean. Bryden's algorithm allows us to obtain a first estimate of $\theta$ from $T$ and pressure values, together with an initial choice of $S$. Armi and Bray's algorithm gives an estimate of $S$ from the first estimate of $\theta$. The procedure is repeated until convergence is obtained in both $\theta$ and $S$ values, and then the potential density $(\rho)$ is calculated. (Hereafter, we will talk indistinctly about $\rho$ and sigma-theta defined as $\sigma_{\theta} \equiv \rho-1000$, with $\rho$ in MKS units; furthermore, we will use the notation of $\sigma_{\theta}$ units with $1 \sigma_{\theta}$ unit $\equiv 1 \mathrm{~kg}$ $\left.\mathrm{m}^{-3}\right)$.

An important property for the upper thermocline waters of the Blake Plateau is the constancy of the $\theta$ $S$ relationship in both Sargasso Sea and Gulf Stream 

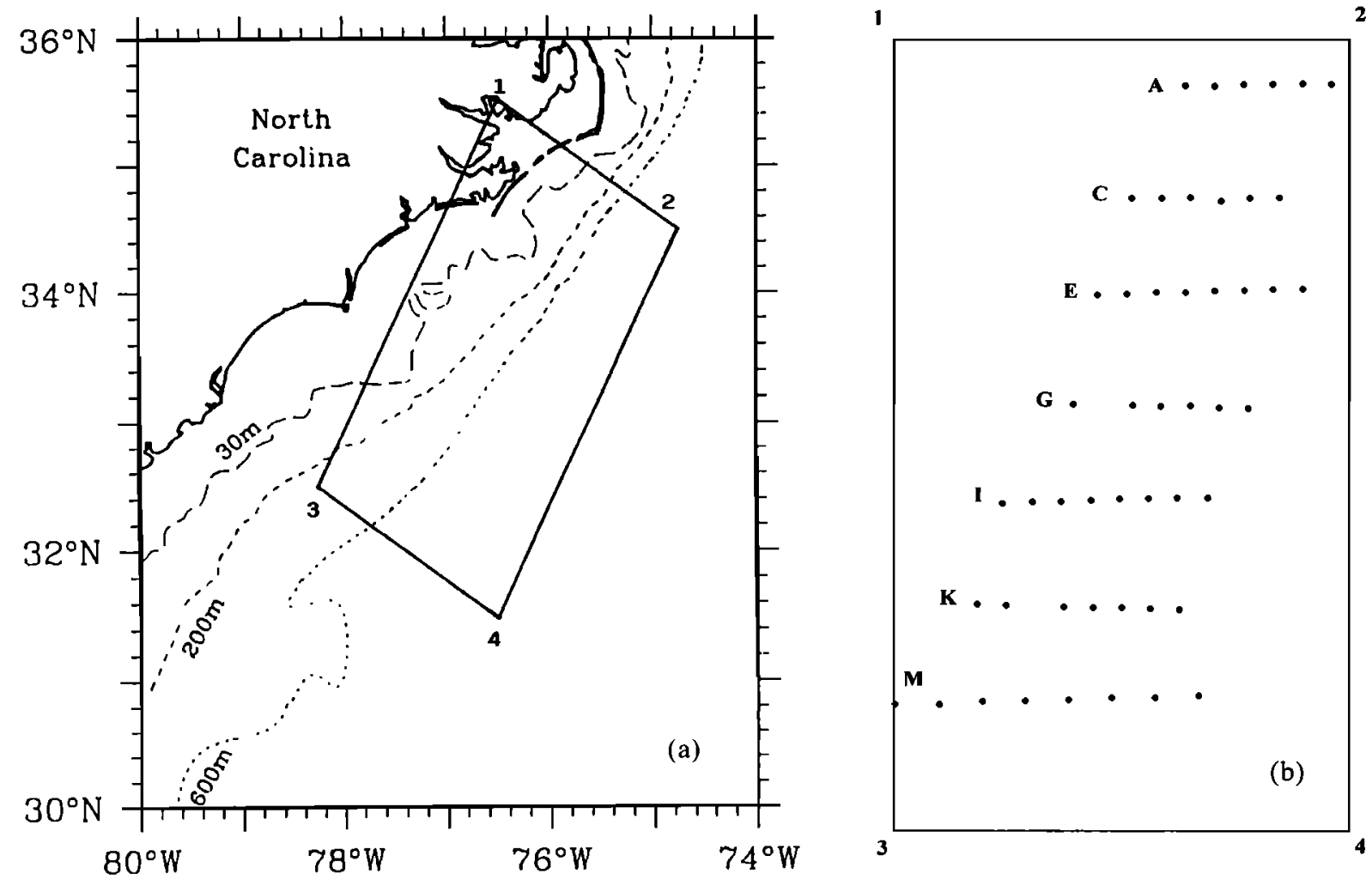

Figure 2. (a) Continental margin of the southeastern United States showing the region of this study. (b) Region after rotation and amplification in the cross-stream direction, with the approximate location of the air-dropped expendable bathythermograph (AXBT) sections.

waters [Richards and Redfield, 1955; Atkınson, 1983], which makes possible the utilization of Armi and Bray's [1983] algorithm. This is not so north of Cape Hatteras where there is substantial lateral mixing between the Gulf Stream and shelf and slope waters [Fisher, 1972; Lillibridge et al., 1990; Churchill et al., 1993: Hitchcock et al., 1994]. Some variability in the $\theta-S$ relationship may appear in our area of study because of northward spreading of Antarctic Intermediate Water along the main axis of the Gulf Stream [Atkinson, 1983], but this occurs at depths larger (usually over $500 \mathrm{~m}$ ) than the maximum depth in our data set. Another source of variability for our area comes from the possibility of thermohaline intrusions from coastal waters, which could cause errors in the estimation of potential density from Armi and Bray's algorithm; this will be examined in section 4 .

The vertical resolution of the AXBTs is one data point every $4 \mathrm{~m}$ down to $200 \mathrm{~m}$, beyond which it decreases to one point every $10 \mathrm{~m}$. With this vertical resolution the number of data points within $0.1 \sigma_{\theta}$ intervals ranges between 2 and more than 20 . The potential density versus depth data have been interpolated at $0.01 \sigma_{\theta}$ intervals, for the $26.2 \leq \sigma_{\theta} \leq 27.2$ range. The density range has been chosen because it is covered by the data in most stations; when this is not the case, however, we have interpolated only over the available data range. The selection of $0.01 \sigma_{\theta}$ intervals has been made as a compromise between vertical resolution and accuracy.
The interpolation procedure uses cubic splines subject to a smoothing tension factor; this procedure removes all depth inversions in the potential density, while at the same time it maintains the smoothing to a minimum in order not to increase excessively the $R i$ values [Miller and Evans, 1985].

A crucial aspect in our analysis will be the spatial interpolation of properties over isolevel/isopycnal surfaces or on cross-stream sections. This interpolation is obtained on a rectangular grid using standard kriging techniques [e.g., Lancaster and Salkauskas, 1986], which provide a value for the interpolation error. In order to improve the procedure of interpolation over the isolevel/isopycnal surfaces, however, we have chosen to rotate the original data set by $30^{\circ}$, such that the AXBT sections are in the direction of one grid axis. Figure $2 \mathrm{~b}$ shows this rotated region which, for better visualization, is also amplified in the cross-stream direction. This region will be used in all our representations of quantities over isolevel (Figure 3) or isopycnal (Figures 4-9) surfaces.

\section{Error Analysis}

\subsection{Sources of Error}

In this Section we analize the potential errors in the AXBT data that may affect all other inferred quantities. There are several error sources, which may be grouped as follows. 

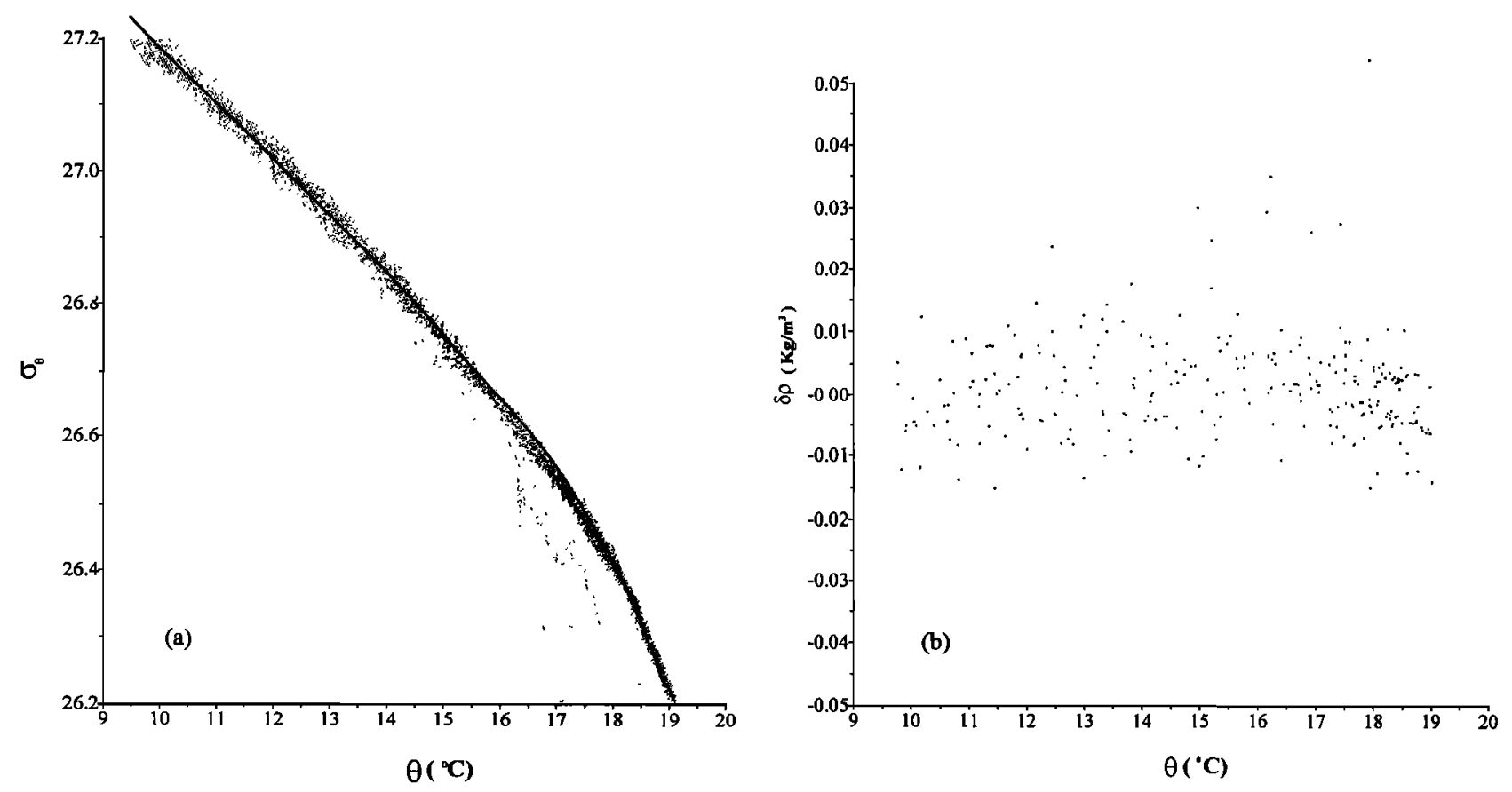

Figure 3. (a) The $\sigma_{\theta}-\theta$ diagram from 25 conductivity-temperature-depth (CTD) stations in our area of study (the three northernmost lines by Atkinson [1983]). The solid line corresponds to Armi and Bray's [1982] empirical algorithm. (b) Individual density errors calculated for the same data set.

4.1.1. Depth and temperature accuracy and resolution. The AXBTs depth accuracy primarily depends on the probe's fall rate. The reported depth accuracy for AXBT probes varies from one manufacturer to another, typical values being \pm 2 and $\pm 5 \%$. The temperature accuracy specification is given in terms of frequency, which the unit transmits from the ocean surface to the aircraft. Several temperature accuracies are reported by different manufacturers, ranging between 0.05 and $0.56^{\circ} \mathrm{C}$. The depth and temperature resolution for AXBT probes are $0.1 \mathrm{~m}$ and $0.01^{\circ} \mathrm{C}$, respectively.

The probes employed were manufactured by Hermes Electronics (J. Bane, personal communication, 1998). They were standard military qualified probes (as is the case with AXBTs manufactured by most companies), which conformed to a fall rate given by $z=1.52 t$, where $z$ is the depth (in meters) attained after an elapsed time $t$ (in seconds) in the water. Unfortunately, however, we have not found any published calibration work on this type of probes. There have been several studies on units manufactured by other companies [Sessions et al., 1976; Bane and Sessions, 1984; Boyd, 1987; Boyd and Linzell, 1993], and although they conform to the same navy specifications, these are of sufficiently different design that we should not expect their calibration information to apply to the Hermes units. One possibility is to take both depth and temperature errors as corresponding to the largest accuracy reported values, i.e., $\pm 5 \%$ the depth value and $0.56^{\circ} \mathrm{C}$. An accuracy value, however, suposedly provides a figure for the maximum error, providing a range that must be satisfied by all probes. Taking the accuracy value as the measured error hence will likely produce an overestimate of the standard error for the temperature and depth. Furthermore, the above studies have shown that typically, the fall rate for AXBT probes would perform better than the above specifications. For both reasons we choose the depth error as $\pm 2 \%$ of the reported depth and the temperature error as $0.2^{\circ} \mathrm{C}$.

4.1.2. Station position. The station position was found with an inertial navigation system (INS) on the aircraft, which had a specified maximum drift rate of $4 \mathrm{~km} \mathrm{hr}^{-1}$ (J. Bane, personal communication, 1998). This means that the maximum error in absolute position is the drift rate times the elapsed time since takeoff, while the maximum error in relative position between two consecutive AXBTs (maximum relative error) is the drift rate times the time between AXBT deployments.

Each AXBT survey was done with the aircraft following cross-stream lines and then moving to the adjacent line. The time difference between consecutive AXBT deployments along a cross-stream line is typically $\sim 2$ $\mathrm{min}$, so the maximum relative error is $130 \mathrm{~m}$. This gives the maximum position error for our calculations of the cross-stream isopycnal slope and all the other quantities that depend on it (e.g., equation (4)).

The maximum time difference between stations in two adjacent lines is typically $\sim 1$ hour, so the maximum relative error in this case would be $4 \mathrm{~km}$. The only role of this error, however, could be to modify the relative position of stations in adjacent lines that could affect the exact contouring of properties over isopycnal 
surfaces. Since $4 \mathrm{~km}$ is much less than the distance between adjacent lines $(\sim 50 \mathrm{~km})$, we may conclude that this error will cause a rather insignificant alteration of the contour lines.

4.1.3. Non-uniqueness of the $\theta-S$ relationship. A unique $\theta-S$ relationship for our area of study would guarantee that given a $\theta$ value, we could obtain the $S$ and $\rho$ values. In our area of study, however, there may be some variability in the $\theta-S$ diagram, probably because of thermohaline intrusions, resulting in a nonunique $\theta-S$ relationship. This means that given a $\theta$ value, there will be some uncertainty on the $S$ value, leading to an error in the estimated $\rho$.

In order to assess the size of this error we have examined a conductivity-temperature-depth (CTD) data set, provided to us by L. Atkinson from Old Dominion University, corresponding to 25 stations done in September 1980 over our area of interest (these actually correspond to the three northernmost sections of Atkinson [1983], Figure 1). In Figure $3 a$ we present the $\sigma_{\theta}-\theta$ diagram obtained with this data, plotted in the $26.2 \leq \sigma_{\theta} \leq 27.2$ range. In Figure $3 \mathrm{a}$ we have also plotted as a solid line the empirical curve obtained using Armi and Bray's [1982] algorithm, which fits the data rather well. From Figure 3a we can also appreciate that there is some spreading in the $\sigma_{\theta}-\theta$ relationship, typically of $\sim 0.05$ $\sigma_{\theta}$ units and increasing toward the surface layers. This could perhaps be our first estimate for the density error, but the following discussion will show that it is actually an overestimate.

Let us call $\Delta \rho$ the density difference between data points (separated by a vertical distance $\Delta z$ ) as calculated from actual $S$ and $\theta$ data and $\Delta \hat{\rho}$ the density difference between the same data points as calculated from $\theta$ data and $S$ values inferred with $A r m i$ and Bray's [1982] algorithm. These two quantities are related through $\delta \rho=|\Delta \hat{\rho}-\Delta \rho|, \delta \rho$ being the actual density error involved in our calculations. We may analyze the above unsmoothed CTD data, selecting a vertical distance $\Delta z=10 \mathrm{~m}$, this being the order of both the vertical distance between our AXBT data points and the vertical size of finestructure in the Gulf Stream [Gregg and Sanford, 1980; Pelegrí and Csanady, 1994]. From the analysis we obtain that $55 \%$ of the data points have $\delta \rho$ below $0.01 \sigma_{\theta}$ units and $85 \%$ have this error below $0.02 \sigma_{\theta}$ units, the mean error being $0.011 \sigma_{\theta}$ units. If we repeat the calculation with $\Delta z=5 \mathrm{~m}$, we find similar numbers: $60 \%$ of the data points have $\delta \rho$ below $0.01 \sigma_{\theta}$ units and $85 \%$ have this error below $0.02 \sigma_{\theta}$ units, the mean error being $0.010 \sigma_{\theta}$ units.

The above values are much smaller than those inferred from Figure 3a, but they still do not take into account the effects of vertical smoothing and relatively low vertical resolution of the analyzed AXBT data. In order to reproduce these effects we have repeated the above calculation for $\Delta z=10 \mathrm{~m}$ after having smoothed the CTD data with a running filter over $10 \mathrm{~m}$. Figure $3 \mathrm{~b}$ shows the results of this computation: in this case, $85 \%$ of the data points have an error below $0.01 \sigma_{\theta}$ units, and $96 \%$ have an error below $0.02 \sigma_{\theta}$ units, the mean error being $0.007 \sigma_{\theta}$ units. The reason for these small $\delta \rho$ values is that the slope of the $\sigma_{\theta}(\theta)$ curve obtained from individual CTD casts is very similar to the slope of Armi and Bray's [1982] empirical curve.

4.1.4. Non-geostrophic displacements. In a study near Cape Hatteras, Johns et al. [1989] have determined that the mean vertical isopycnal displacements due to internal tides range between $\sim 2 \mathrm{~m}$ offshore and $\sim 6 \mathrm{~m}$ near the Gulf Stream north wall. These small displacements are consistent with the small size of tidal current fluctuations in the northern Blake Plateau, which according to Brooks and Bane [1981], account for only $\sim 10 \%$ of the variance in the along-stream velocity component. These results suggest that the fluctuations in the isopycnals' depth due to internal tides should be relatively small as compared with the isopycnal displacements between adjacent stations. The size of this error may be estimated as the fraction of the mean vertical displacement due to baroclinic tides divided by the mean depth difference of one isopycnal in two adjacent stations (in the cross-stream direction), i.e., $\delta z / \Delta z \simeq(5$ $\mathrm{m} / 50 \mathrm{~m})=0.1$. Note that this error will appear when calculating $\partial z / \partial x$ but not when computing $j$.

4.1.5. Indirect errors. The indirect errors are those related to the calculation of $\partial z / \partial x$ along surfaces that because of the above errors, are not truly isopycnals. Let us temporarily call the calculated potential density as $\hat{\rho}$, where the depth of a water particle is given by $z=z[x, y, \hat{\rho}(x, y, \rho, t), t]$. In this case the slope of the isopycnals and the slope of constant $\hat{\rho}$ surfaces are related through

$$
\left.\frac{\partial z}{\partial x}\right|_{\rho}=\left.\frac{\partial z}{\partial x}\right|_{\hat{\rho}}+\left.\frac{\partial z}{\partial \hat{\rho}} \frac{d \hat{\rho}}{d x}\right|_{\rho} .
$$

This shows that the error in the slope of an isopycnal must actually be increased with the second term in the right-hand side of (8).

\subsection{Error Propagation}

The maximum errors in the mixing properties may be estimated using a standard error propagation analysis [e.g., Sánchez del Río, 1989]. With this procedure we obtain the following expressions for the errors in the separation index $(\delta j)$, the isopycnal slope $(\delta h)$, and the Richardson number $(\delta R i)$ :

$$
\begin{aligned}
\delta j & =J\left(\delta \rho+\rho \frac{\delta z}{\Delta z}+\rho \frac{\delta \rho}{\Delta \rho}\right), \\
\delta h & =h\left(\frac{\delta z}{\Delta z}+\frac{\delta x}{\Delta x}\right)+\delta h_{a}+\delta h_{i}, \\
\delta R i & =\frac{f^{2}}{g h^{2}} \delta j+\frac{2 f^{2} j}{g h^{3}} \delta h .
\end{aligned}
$$

For convenience we have introduced here the slope of an isopycnal, $h \equiv \partial z / \partial x$, which is related to the diapycnal shear, $s \equiv \partial v / \partial \rho$, through the thermal wind equation, $\rho f s=g h$. In these expressions, $\Delta z, \Delta \rho$, and $\Delta x$ represent the changes in $z, \rho$, and $x$, respectively, employed to evaluate $j$ and $h$ from field data (all the other rel- 
evant quantities are derived from these two), while $\delta z$, $\delta \rho$, and $\delta x$ represent the field errors involved in measuring $\Delta z, \Delta \rho$, and $\Delta x$, respectively. Finally, $\delta h_{a}$ and $\delta h_{i}$ are the errors arising from ageostrophic isopycnal displacements and indirect errors, respectively.

The density error $\delta \rho$ will be the result of limitations in temperature resolution and variability in the $\theta-S$ relationship. The mean error due to variability in the $\theta$ $S$ relationship was estimated in section 4.1 as $0.007 \sigma_{\theta}$ units. The error due to temperature resolution may be estimated using a linear approximation for density in terms of temperature and salinity and for salinity in terms of temperature. In this manner we obtain $\delta \rho=C \delta T$, with $C \simeq 0.3 \sigma_{\theta}$ units ${ }^{0} \mathrm{C}^{-1}$. The value for $\delta T$ is estimated by appreciating that this quantity appears only when calculating $\delta j$, so it refers to one single AXBT. For this reason we choose $\delta T$ as the resolution error for temperature readings when calculating $\rho$ (i.e., $\delta T=0.01^{\circ} \mathrm{C}$ ) and as twice this number when computing $\Delta \rho$, with the two factor arising because of the possible addition of errors when calculating differences; these would correspond to the first and third terms in the right-hand side of (9), respectively. The error involved in the last term of (9) is, however, the only potentially important error (it is larger than the first term by a factor $\rho / \Delta \rho$ ), and according to the previous approximations it is given by $\delta \rho \simeq 0.006 \sigma_{\theta}$ units. The error due to the joint effect of temperature resolution and $\theta-S$ variability is simply calculated as the addition of the above individual estimates, resulting in $\delta \rho=0.013 \sigma_{\theta}$ units.

The depth error $\delta z$ will depend on the variable that is evaluated: $\delta j$ is calculated from one single AXBT data, while $\delta h$ is evaluated from data of two adjacent AXBTs. In the first case the error is estimated as $\delta z=0.04 \Delta z$. In the second case it is approximated by $\delta z=0.04 \bar{z}+5$ $m$, where $\bar{z}$ is the mean depth (in meters) along an isopycnal for two adjacent AXBTs and $5 \mathrm{~m}$ corresponds to the mean isopycnal displacement caused by internal tides. In both cases the 0.04 coefficient corresponds to twice the accuracy in the probes' fall rate, again taking into account the possible addition of errors. We finally note that the position error is $\sim 130 \mathrm{~m}$, which causes $\delta x / \Delta x$ to be a small quantity, $\sim(130 \mathrm{~m} / 12 \mathrm{~km}) \simeq 0.01$.

After the above considerations we can write the following expressions for $\delta j, \delta R i$, and the error in diapycnal shear $(\delta s)$ :

$$
\begin{aligned}
\delta j & =j\left(\frac{\delta \rho}{\rho}+\frac{\delta z}{\Delta z}+\frac{\delta \rho}{\Delta \rho}\right) \\
& \equiv \delta j_{1}+\delta j_{2}+\delta j_{3} \\
\delta s & =s\left(\frac{\delta \rho}{\rho}+\frac{\delta z}{\Delta z}+\frac{\delta x}{\Delta x}+\frac{\delta \rho}{\Delta \rho}\right) \\
& \equiv \delta s_{1}+\delta s_{2}+\delta s_{3}+\delta s_{4} \\
\delta R i & =R i\left(\frac{\delta j}{j}+\frac{\delta \rho}{\rho}+\frac{2 \delta s}{s}\right) \\
& \equiv \delta R i_{1}+\delta R i_{2}+\delta R i_{3}
\end{aligned}
$$

where $\delta j_{1} \equiv j \delta \rho / \rho<10^{-5} j, \delta j_{2} \equiv j \delta z / \Delta z \simeq 0.04 j$, $\delta j_{3} \equiv j \delta \rho / \Delta \rho, \delta s_{1} \equiv s \delta \rho / \rho<10^{-5} s, \delta s_{2} \equiv s \delta z / \Delta z \simeq$ $0.04 s(\bar{z} / \Delta z+0.1), \delta s_{3} \equiv s \delta x / \Delta x \simeq 0.01 s, \delta s_{4} \equiv$ $s \delta \rho / \Delta \rho, \delta R i_{1} \equiv R i \delta j / j, \delta R i_{2} \equiv R i \delta \rho / \rho$, and $\delta R i_{3} \equiv$ $2 R i \delta s / s$. The previous coefficients apply for all quantities in the MKS system.

The main contribution to $\delta j$ is $\delta j_{3}$, which arises from the $\delta \rho / \Delta \rho$ fraction. This fraction may be estimated as $(J \delta \rho) / \Delta z=(j \delta \rho) /(\rho \Delta z)$; choosing $\Delta z=10 \mathrm{~m}$ as the vertical distance over which AXBT data points are approximately independent, using $\delta \rho \simeq 0.01 \sigma_{\theta}$ units, and having a typical $j$ value of $10^{5} \mathrm{~m}$ (section 5), we obtain a characteristic $\delta \rho / \Delta \rho$ value of $\sim 0.1$. The main contribution to $\delta s$ is $\delta s_{2}$, which is mostly related to possible errors in the probes' fall rate. Here $\delta s_{2}$ may be potentially important with increasing depth and for isopycnals of little slope because it depends on the fraction $(\bar{z} / \Delta z)$. The main potential contribution to $\delta R i$ is $\delta R i_{3}$, being twice the error in $s$.

We may summarize the above analysis by saying that the principal error source for $j$ is related to variability in the $\theta-S$ relation, while for both $s$ and $R i$ the main error is related both to possible errors in the probes' fall rate and to $\theta-S$ variability. One additional consideration is that all $K_{v}, w_{\rho}$, and $\partial w_{\rho} / \partial \rho$ are functions of $R i$ (in some instances, a high-order function), which causes their relative errors to be usually much larger. For example, in subcritical regions the error in the vertical density diffusivity will be $\delta K_{v} / K_{v} \simeq 9 \delta R i / R i$ (equation (5)).

Besides the above errors, we have to keep in mind that there are intrinsic limitations related to the horizontal resolution and vertical smoothing of the data. For example, large station spacing and excesive vertical smoothing will usually lead to overestimates of the Richardson number. Another limitation is related to the uncertainties in the $K_{v}$ parameterization. Figure 1 shows only a few of many possible parameterizations but clearly illustrates that $K_{v}$ could change by as much as 1 order of magnitude depending on the selection. According to these considerations it is clear that our analysis of the distributions over a vertical section or an isopycnal surface must be mainly qualitative, looking at spatial and temporal patterns rather than at absolute numbers.

\subsection{Monte Carlo Simulation}

The above error propagation technique leads to estimates of maximum errors because it accumulates each individual error. In practice, however, some errors often will tend to compensate each other, and the final error will be much smaller. In this section we further pursue the issue of estimating errors, now through a Monte Carlo-style approach that produces more realistic values than those obtained with the error propagation technique.

The Monte Carlo method assumes that the measured variables indeed provide the true values, and it uses appropriate distributions that mimic the measurement errors in order to obtain a set of new simulated values [e.g., Hammersley and Handscomb, 1964]. The under- 
lying hypothesis is that the way in which the random errors contribute to the measured variable does not vary rapidly as a function of the true value, so the measured one is a reasonable surrogate.

In this analysis we have simulated, for every point in all $z$ and $j$ vertical sections, a sample set of 5000 values. This has been done both in the $(x, \rho)$ coordinates and in the $z$ and $j$ values using a uniform distribution within the following ranges: $\delta x=130 \mathrm{~m}, \delta \rho=0.01 \sigma_{\theta}, \delta z=$ $0.04 z$, and $\delta j=0.1 j$. For example, for every measured $z$ we have simulated 5000 new $z_{i}$ values within the range $z-\delta z<z_{i}<z+\delta z$. The ranges $\delta x, \delta \rho$, and $\delta z$ are those arising from the discussion in section 4.1, while the $\delta j$ range follows from the discussion in section 4.2.

Using the simulated values we have calculated at each point a sample of 5000 new values for both the diapycnal shear $\partial v / \partial \rho$ and the gradient Richardson number $R i$. The error in each variable may be estimated as the standard deviation of the sample set generated at each point, and the relative error becomes the fraction between this standard deviation and the value initially calculated at that point. The results obtained with this method lead to errors considerably smaller than those obtained with the error propagation procedure, confirming that the propagation method provides a measure of the maximum errors arising from the data analysis.

\section{Results}

Bane et al. [1981, Figures 4 and 8] presented the surface temperature distribution for all five surveys as well as the temperature distribution at 100,250 , and $350 \mathrm{~m}$ for February 11. The temperature distributions clearly showed the progression of two large-amplitude meanders (which they called Bert and Ernie) through the region, with warm water filaments, or streamers, detaching from the crest of meanders into the cyclonic side of the stream. In these cases a dome of cold water, or a cold eddy, is formed between the filaments and the core of the Gulf Stream, usually at a trough of a meander. The filaments, however, are less evident with increasing depth and totally vanish at depths of $\sim 250$ m.

In Figure 4 we show the distribution of $\sigma_{\theta}$ at $200 \mathrm{~m}$ for all five surveys (the dots show the location of stations with water depth s $200 \mathrm{~m}$ ). The filaments are not visible at this depth, and the meanders are considerably smoothed because of the compensating effect of salinity on density (in the western North Atlantic salinity decreases with depth) to the point where they are difficult to identify. A major meander, Ernie, is visible February 11, with its trough on section $\mathrm{K}$ and its crest between sections I and G; by February 14, Ernie's crest has propagated to somewhere between sections $\mathrm{E}$ and C. A more detailed description of this and other meanders will be given below.

Figures 5-9 show the distribution of several mixing properties, for all surveys, over the $\sigma_{\theta}=26.34$ surface, with the dots showing the location of stations where water of this density is found. (Please note that in these and Figures 13-15 we have chosen to plot the logarithm distributions for the Richardson number, the density tendency, and the diapycnal convergence, because this greatly clarifies the plots, at the expense of some numerical smoothing in the maxima caused by the contouring routines.) Figures 5 and 6 show the distribution, for the February 11 and 17 surveys, of the following six quantities: depth $z$, separation index $j$, diapycnal shear $\partial v / \partial \rho$, gradient Richardson number $R i$, density tendency $w_{\rho}$, and diapycnal convergence/divergence $\partial w_{\rho} / \partial \rho$. Figures 7-9, however, show the distribution of only two quantities $(j$ and $R i$ ) for the remaining three surveys. The reason for showing a more complete set of quantities only for the February 11 and 17 surveys is for the sake of brevity and because they correspond to the two opposite situations that we want to compare: the presence of two large meanders February 11 versus no significant meander activity February 17.

The depth distribution of the $\sigma_{\theta}=26.34$ isopycnal (Figures 5a and 6a) is also rather smooth in all stations. In Figure 5a (February 11) the meanders Bert and Ernie have their crests near sections $C$ and I, respectively, while their troughs lie somewhere between sections $E$ and $G$ and near section $K$, respectively. The shallowing of this layer in the central portion of section $\mathrm{K}$ is indicative of a dome of cold water, while its deepening closer to the coast is indicative of a filament that emanated from the crest of meander Ernie. In Figure $6 \mathrm{a}$, on the other hand, we may appreciate that on February 17 both meanders have traveled away from the region.

The distribution of the separation index $j$ over a shallow upper thermocline isopycnal (Figures 5b, 6b, 7a, $8 a$, and $9 a$ ) is a much better indicator of the meanders and filaments in the region: upwelling isopycnals are closely packed (relatively low $j$ ). An adequate threshold value showing the location of these rising isopycnals is $j=20 \times 10^{4} \mathrm{~m}$ (surfaces separated by $0.1 \sigma_{\theta}$ units are $20 \mathrm{~m}$ apart), which is shown as a thick line in Figures $5 b, 6 b, 7 a, 8 a$, and $9 a$ (and as a thick broken line in the remaining parts of Figures 5-9). This isoline clearly follows the evolution of the meanders over the region. On February 9 the crest of Bert is near section K (Figure 7a), while by February 11 it has propagated to section $\mathrm{C}$ and the crest of Ernie is between sections $I$ and $\mathrm{G}$ (Figure 5b). On February 14, Bert is already out of the region, while Ernie's crest has moved to between sections $\mathrm{C}$ and $\mathrm{E}$ (Figure 8a). On February 15 the crest of Ernie is located near section C (Figure $9 \mathrm{a}$ ), while on February 17 it has finally left the region (Figure $6 \mathrm{~b}$ ). It is important to note that after the passage of these two meanders, there were still two small-amplitude oscillations going through the region: the crest of the first one propagated through sections $\mathrm{K}, \mathrm{G}$, and E February 14, 15 , and 17 , respectively, while the crest of the second one was located near section K on February 17 [see also Bane et al., 1981, Figures 2 and 8].

The estimates for diapycnal shear, for the February 

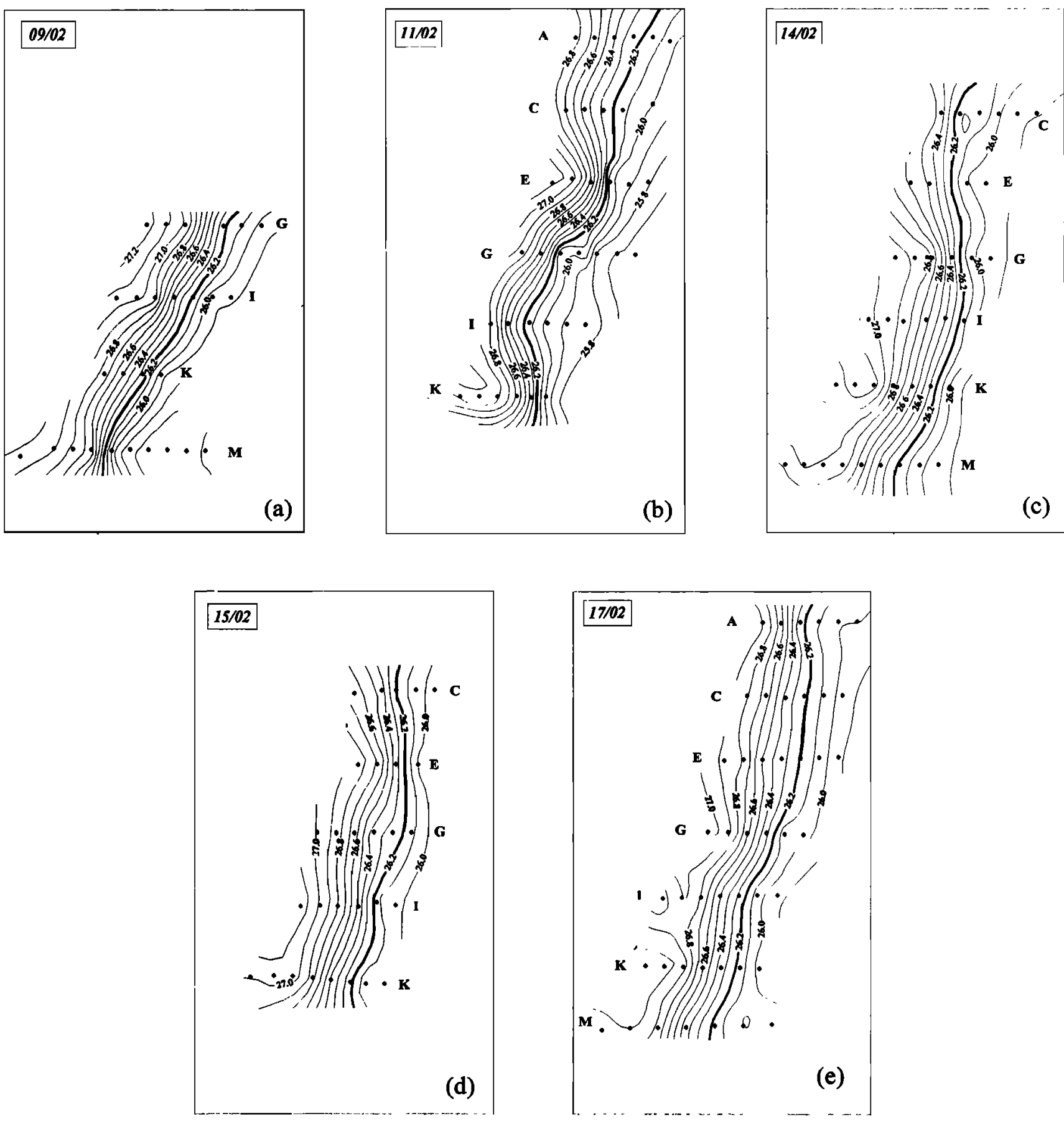

Figure 4. Sigma-theta $\sigma_{\theta}$ distribution at $200 \mathrm{~m}$ during February 1979, days (a) 9, (b) 11, (c) 14, (d) 15 , and (e) 17.

11 and 17 surveys, are quite different (Figures $5 c$ and $6 \mathrm{c}$; the $\partial v / \partial \rho=0.6 \mathrm{~m}^{4} \mathrm{~kg}^{-1} \mathrm{~s}^{-1}$ isoline is plotted there as a thick solid line). Figure $5 \mathrm{c}$ shows broad regions with relatively high diapycnal shear (maximum values of $1.2 \mathrm{~m}^{4} \mathrm{~kg}^{-1} \mathrm{~s}^{-1}$ ), associated with the location of meanders, while Figure $6 \mathrm{c}$ shows that in the absence of large meanders these regions are much more restricted, and the maximum values are somewhat smaller $\left(0.8 \mathrm{~m}^{4}\right.$ $\mathrm{kg}^{-1} \mathrm{~s}^{-1}$ ). Notice that these maxima mainly take place oceanward of the well packed isopycnals, i.e., in regions where $J$ is relatively large, because $\partial v / \partial \rho=J \partial v / \partial z$. Filaments may be associated with large vertical shear (Brooks and Bane [1983] reported countercurrents at the filaments as large as $0.5 \mathrm{~m} \mathrm{~s}^{-1}$ ), but they spread over well-stratified regions (low $J$ ), and the corresponding diapycnal shear is moderate.

The main temporal and spatial patterns may be appreciated through the distribution of the gradient Richardson number (Figures 5d, 6d, 7b, 8b, and 9b). In many senses, Figures $5 d, 6 d, 7 b, 8 b$, and $9 b$ reflect the 

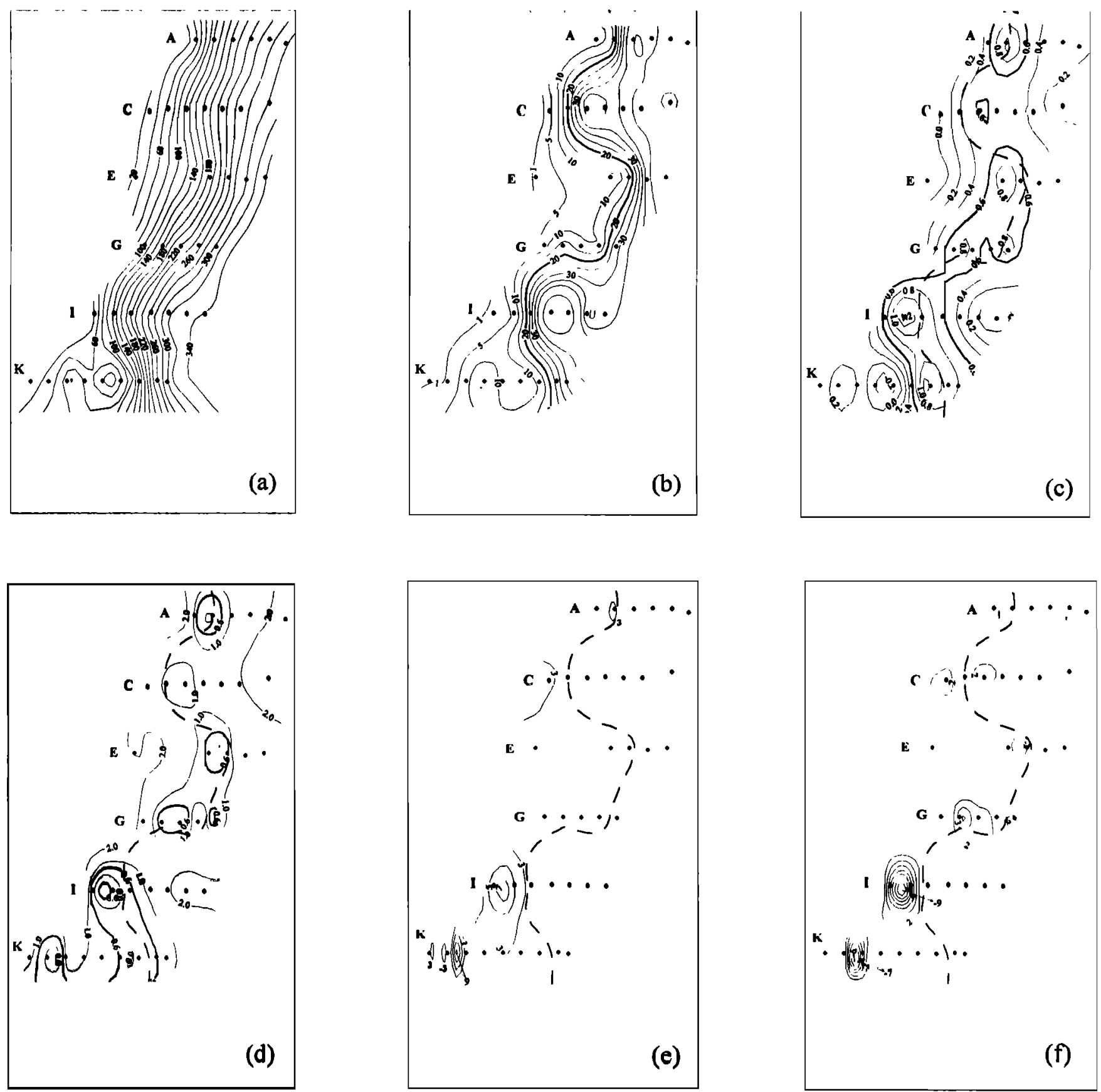

Figure 5. February 11 distribution over the $\sigma_{\theta}=26.34$ surface of (a) depth $z$, (b) separation index $j\left(10^{4} \mathrm{~m}\right)$, where the thick line corresponds to $j=20 \times 10^{4} \mathrm{~m}$, (c) diapycnal shear $\partial v / \partial \rho$ $\left(\mathrm{m}^{4} \mathrm{~kg}^{-1} \mathrm{~s}^{-1}\right)$, where the thick line corresponds to $\partial v / \partial \rho=0.6 \mathrm{~m}^{4} \mathrm{~kg}^{-1} \mathrm{~s}^{-1}$, (d) the logarithm of the Richardson number $\log R i$, where the thick line corresponds to $\log R i=0.6(R i=4)$ and to $\log R i=-0.6(R i=0.25)$, (e) the logarithm of density tendency $w_{\rho}$ (units are such that $\log$ $w_{\rho}=n$ means $w_{\rho}=\operatorname{sgn}(n) 10^{|n|-10} \mathrm{~kg} \mathrm{~m}^{-3} \mathrm{~s}^{-1}$ ), and (f) the logarithm of diapycnal convergence/divergence $\partial w_{\rho} / \partial \rho$ (units are such that $\log \left(\partial w_{\rho} / \partial \rho\right)=n$ means $\partial w_{\rho} / \partial \rho=\operatorname{sgn}(n) 10^{|n|-8}$ $\mathrm{s}^{-1}$ ). In Figures $5 \mathrm{c}, 5 \mathrm{~d}, 5 \mathrm{e}$, and $5 \mathrm{f}$ the $j=20 \times 10^{4} \mathrm{~m}$ isoline is plotted as a thick broken line.

distribution of diapycnal shear because of the quadratic dependence of $R i$ on $\partial v / \partial \rho$ (equation (4)), but they also illustrate the important role of the separation index. The logarithm values given by $-0.6(R i=0.25)$ and $0.6(R i=4)$ are presented as thick solid lines to help visualize this evolution. Figures $5 \mathrm{~d}$ and $7 \mathrm{~b}$ show the existence of $R i<4$ over widespread areas, mainly over the crest and filament of meander Ernie but also at the trough of meander Bert. In particular, we may see that the absolute minimum, beyond subcritical $(R i<0.25)$, is attained at Ernie's crest because of both low $j$ and high $\partial v / \partial \rho$. Figures $6 \mathrm{c}, 8 \mathrm{~b}$, and $9 \mathrm{~b}$ suggest moder- 

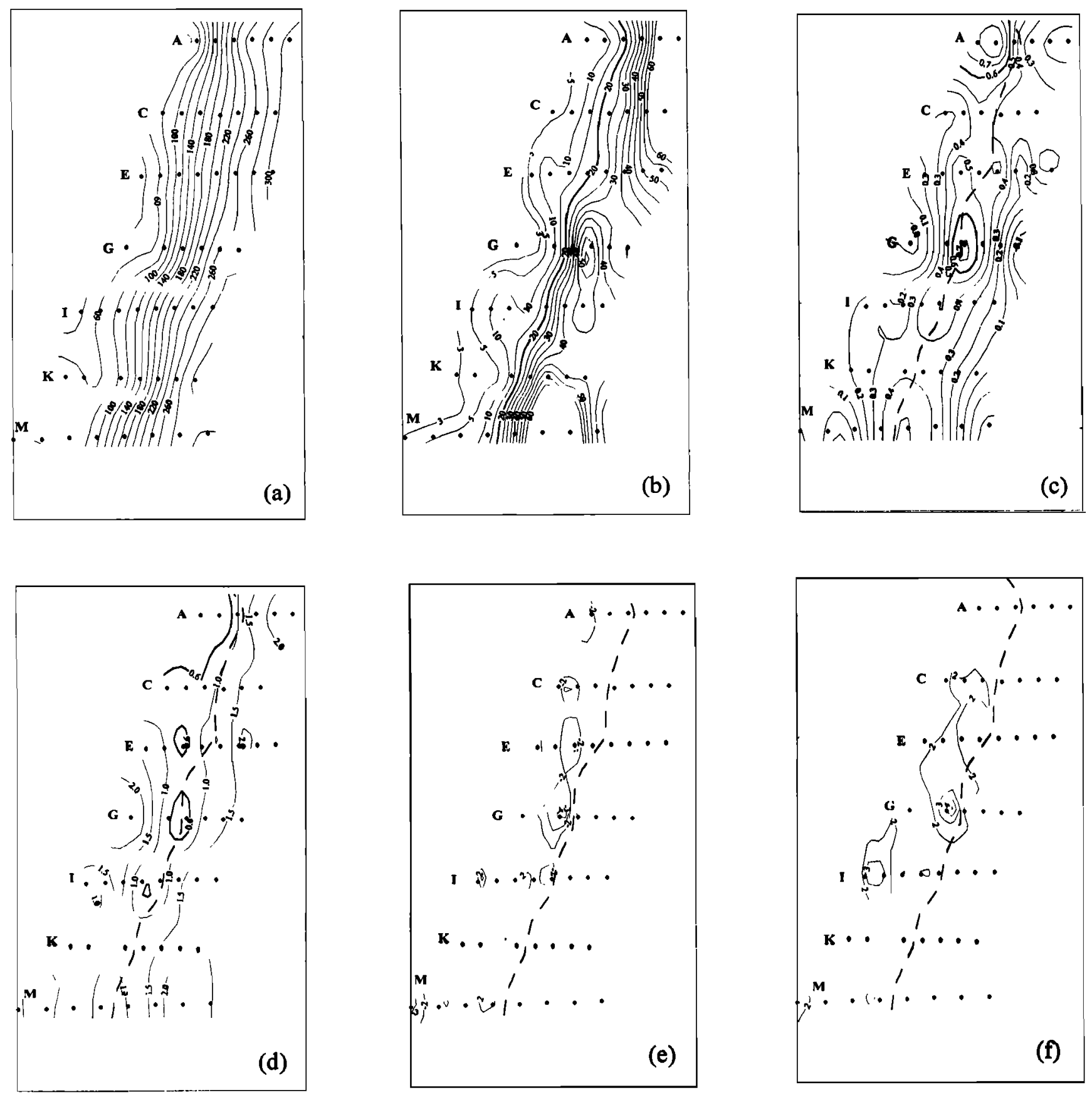

Figure 6. As in Figure 5 but for February 17.

ate dynamic stability, with $R i$ typically $\sim 10$ and some scattered values below 4, possibly associated both with meander Ernie before it leaves the region and with the small-amplitude oscillations that are present in the area during February 14, 15, and 17.

Figure 10 presents the distribution of the maximum relative errors in diapycnal shear $(\delta s / s)$ and the Richardson number $(\delta R i / R i)$ over the $\dot{\sigma}_{\theta}=26.34$ surface for the February 11 survey. The error in the separation in$\operatorname{dex}(\delta j)$ is everywhere on this surface smaller than $0.3 j$ and is not shown. Figure 10a shows that $\delta s$ ranges between $0.1 s$ and $0.3 s$ in most of the domain but reaches maximum values of $0.7 \mathrm{~s}$ in the offshore regions, where the isopycnal surface is deep and rather flat. Figure $10 \mathrm{~b}$ shows a similar picture for $\delta R i$ but with values about twice as large $(0.2 R i$ to $0.6 R i)$ in most of the domain. The $\delta R i / R i$ values over 0.6 are constrained to the deep offshore portion of the surface. Figure 11 presents the $\delta s / s$ and $\delta R i / R i$ distributions as calculated using the Monte Carlo method. Both methods lead to similar error patterns, with the Monte Carlo simulation leading to values about half those obtained with the propagation method. The main conclusion is that the errors are significant but should not affect the qualitative pat- 

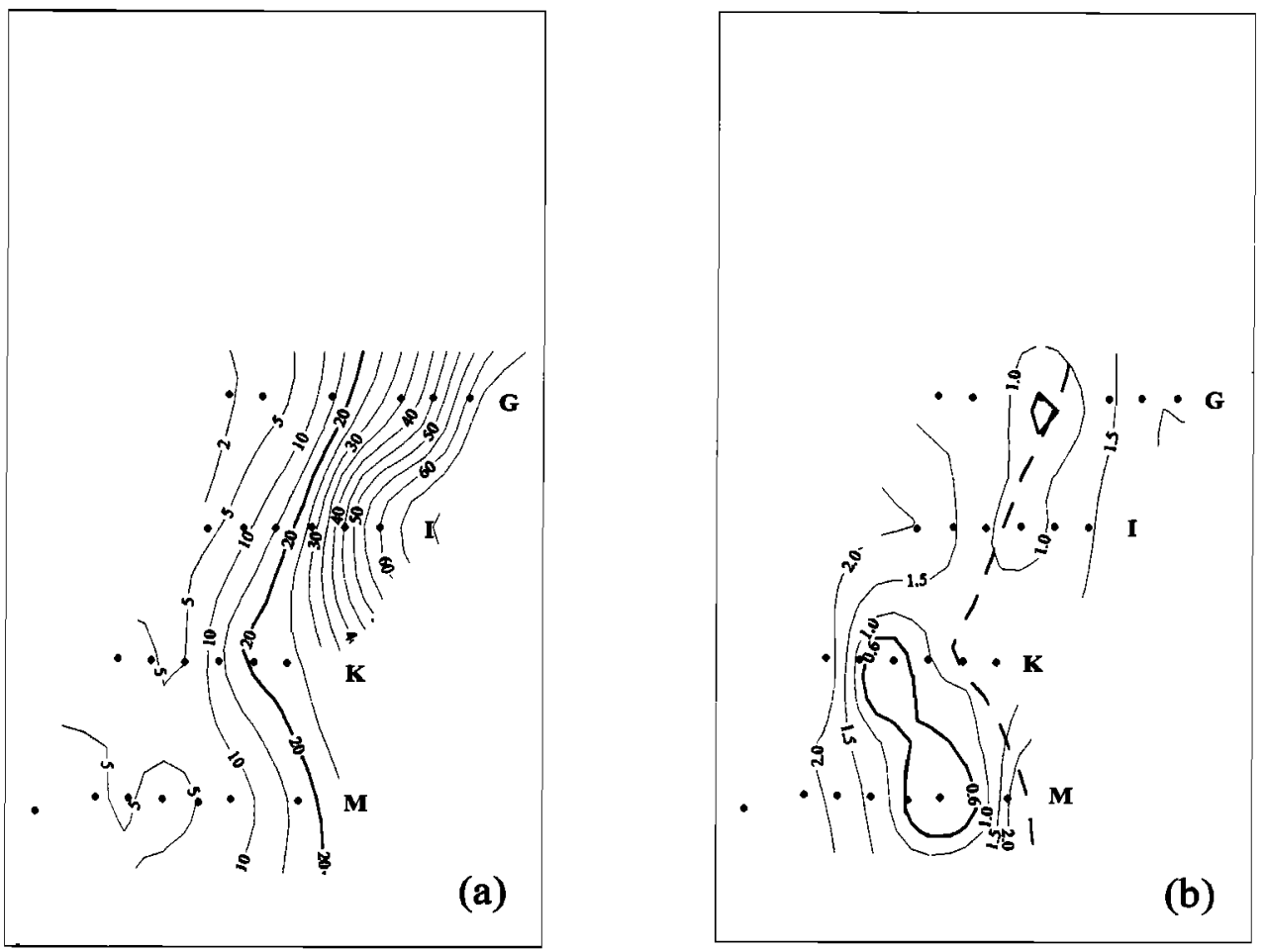

Figure 7. February 9 distribution over the $\sigma_{\theta}=26.34$ surface of (a) the separation index $j\left(10^{4}\right.$ $\mathrm{m})$ and (b) the logarithm of the Richardson number log $R i$, where the thick line corresponds to $\log R i=0.6(R i=4)$ and to $\log R i=-0.6(R i=0.25)$. The $j=20 \times 10^{4} \mathrm{~m}$ isoline is plotted as a thick broken line.
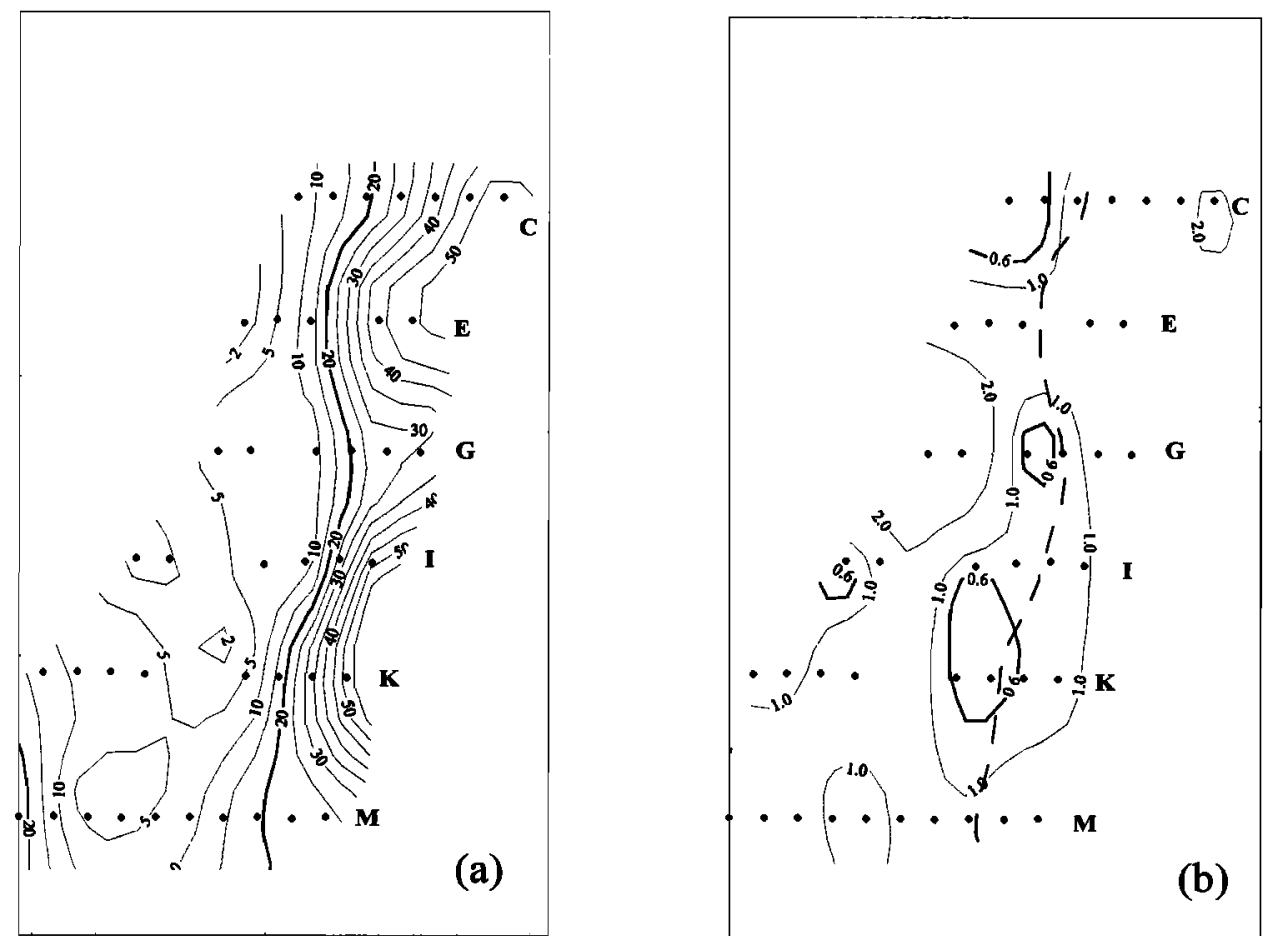

Figure 8. As in Figure 7 but for February 14. 

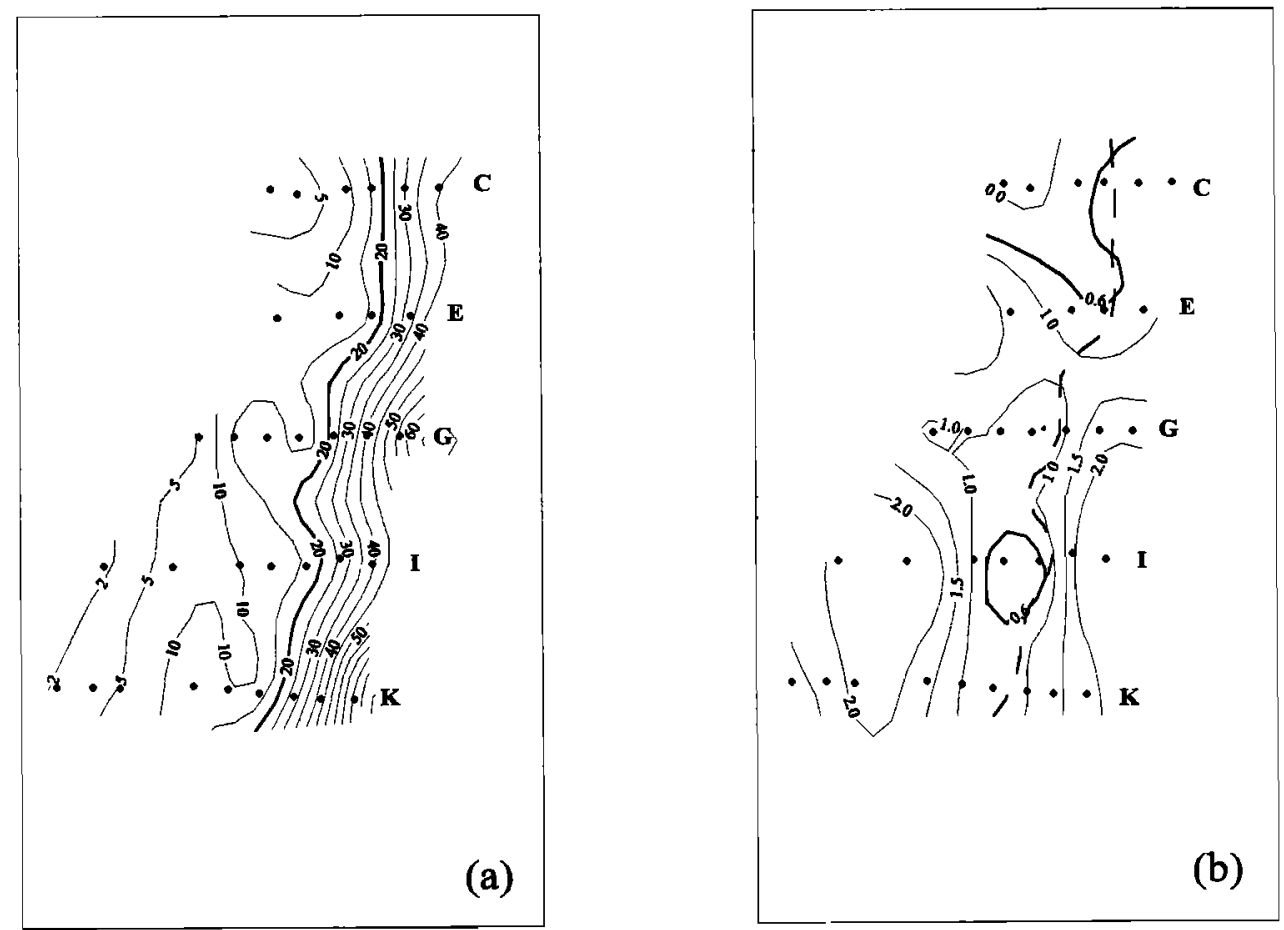

Figure 9. As in Figure 7 but for February 15.
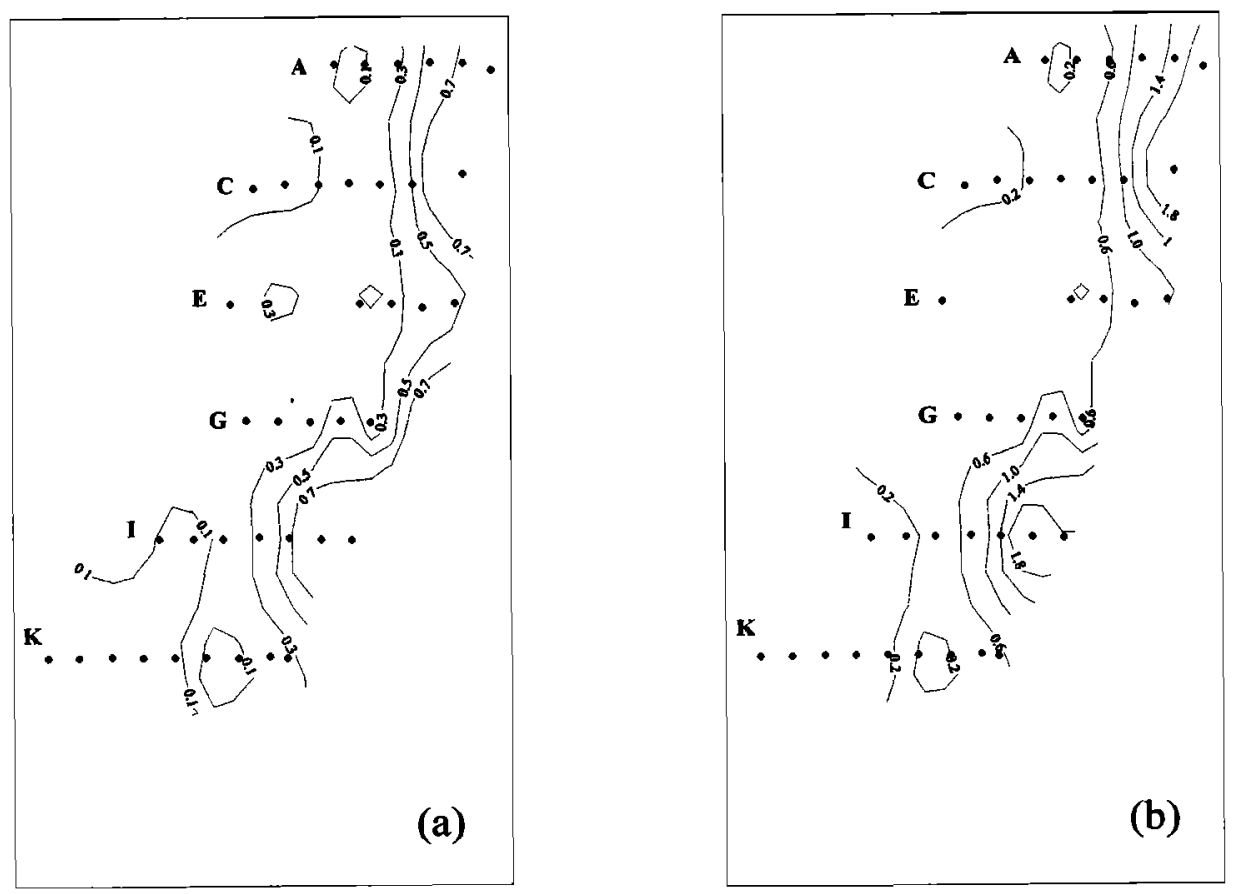

Figure 10. February 11 distribution over the $\sigma_{\theta}=26.34$ surface of (a) maximum relative error in the diapycnal shear $\delta s / s$ and (b) maximum relative error in the Richardson number $\delta R i / R i$. 

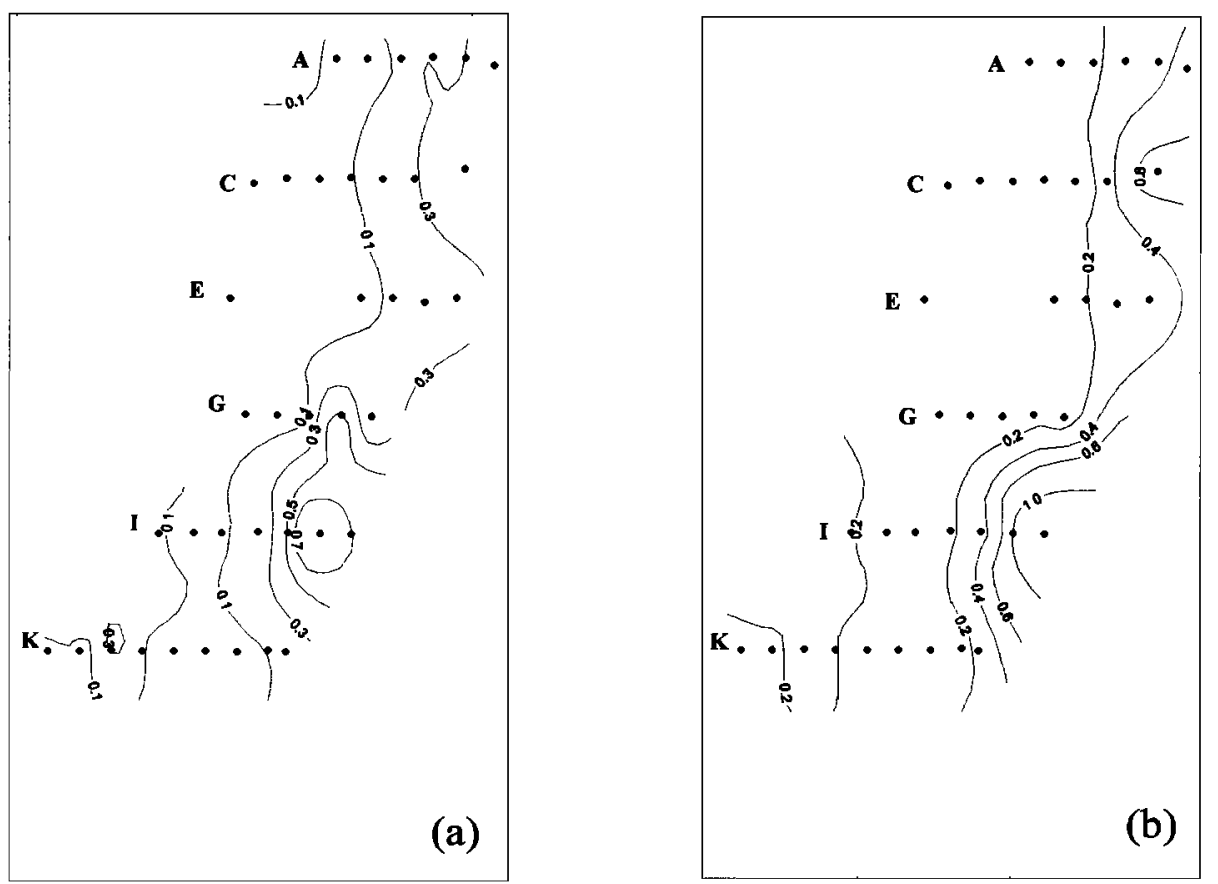

Figure 11. February 11 distribution over the $\sigma_{\theta}=26.34$ surface of (a) relative error in the diapycnal shear $\delta s / s$ as obtained using the Monte Carlo method and (b) relative error in the Richardson number $\delta R i / R i$ as obtained using the Monte Carlo method.

terns extracted from the variable distributions, with the largest errors being found in the deepest regions and far away from meander activity.

The density tendency and diapycnal convergence are calculated using the parameterization described in section 2, and the results are presented in Figures 5e, 5f, $6 \mathrm{e}$, and $6 \mathrm{f}$. Maximum absolute values take place over Ernie's crest and its filament on February 11. The high values over the filament are related to the closely packed isopycnals near the continental shelf (recall the strong dependence of the density tendency with $J$ in (3)). The high values at the crest are clearly related to subcritical $R i$ there.

The diapycnal (or entrainment) velocity is related to the density tendency by $w_{d}=J w_{\rho}$ [Pelegri and Csanady, 1994]. This implies that the diapycnal velocity, responsible for vertical mass and nutrient transfer, is further modulated by stratification. For example, the density tendencies are very high over both the crest and filament of a meander, but the diapycnal velocities may also be important in offshore upper thermocline layers where stratification is not so intense. Using the values in Figures 5 and 6 (but keeping in mind the note of caution expressed at the end of section 4.2), we may obtain diapycnal velocities as large as $10^{-2} \mathrm{~m} \mathrm{~s}^{-1}$ over the crest and of order $10^{-5} \mathrm{~m} \mathrm{~s}^{-1}$ farther offshore. At the filament the corresponding diapycnal velocities would be even larger, $\sim 0.5 \mathrm{~m} \mathrm{~s}^{-1}$. The accuracy of this very large values is questionable because the filament region has poor resolution in the density coordinate, but it is indicative of active mixing.

In Figures 12-15 we present the distribution of the mixing properties on three selected sections across the
Gulf Stream. In Figure 12 we turn momentarily to the vertical coordinate system in order to show the $\sigma_{\theta}$ distribution for sections $K$ and I during February 11 and for section K during February 17. In Figures 13, 14, and 15 we are back to the isopycnic system to show the distribution of $z, j, \partial v / \partial \rho, R i, w_{\rho}$, and $\partial w_{\rho} / \partial \rho$ for these same sections. In order to ease intercomparison, Figures 12-15 are plotted to the same horizontal and vertical/isopycnic scales. The $j=20 \times 10^{4} \mathrm{~m}$ isoline is presented in part $b$ of Figures 12-15 as a thick solid line, while in parts c-f it is also plotted for reference as a thick broken line. In part $c$ of Figures 12-15 the $\partial v / \partial \rho=0.6$ $\mathrm{m}^{4} \mathrm{~kg}^{-1} \mathrm{~s}^{-1}$ isoline is plotted as a thick solid line, while in part $\mathrm{d}$ of these same Figures the $\log R i=0.6$ and -0.6 contours ( $R i=4$ and 0.25 , respectively) are also plotted as thick solid lines.

Figure 12a corresponds to section $\mathrm{K}$, taken approximately across the trough of meander Ernie during February 11, while Figure 12b corresponds to section I, taken across the crest of meander Ernie that same day. Figure 12c shows the distribution on section $\mathrm{K}$ as characteristic of low meander activity during February 17. The frontogenetical character of the density structure associated with the meanders is clear as compared with much lower horizontal density gradients during the last day. Figures 13 and 14 correspond to the isopycnic distributions across sections $K$ and I (trough and crest of meander Ernie, respectively) February 11. Figures 13 and 14 suggest some interesting features associated with the passage of meanders. On section K (Figure 13) the minimum (subcritical) $R i$ values clearly correspond to the filament, where diapycnal shear is moderately low but the isopycnals are closely packed. A secondary 

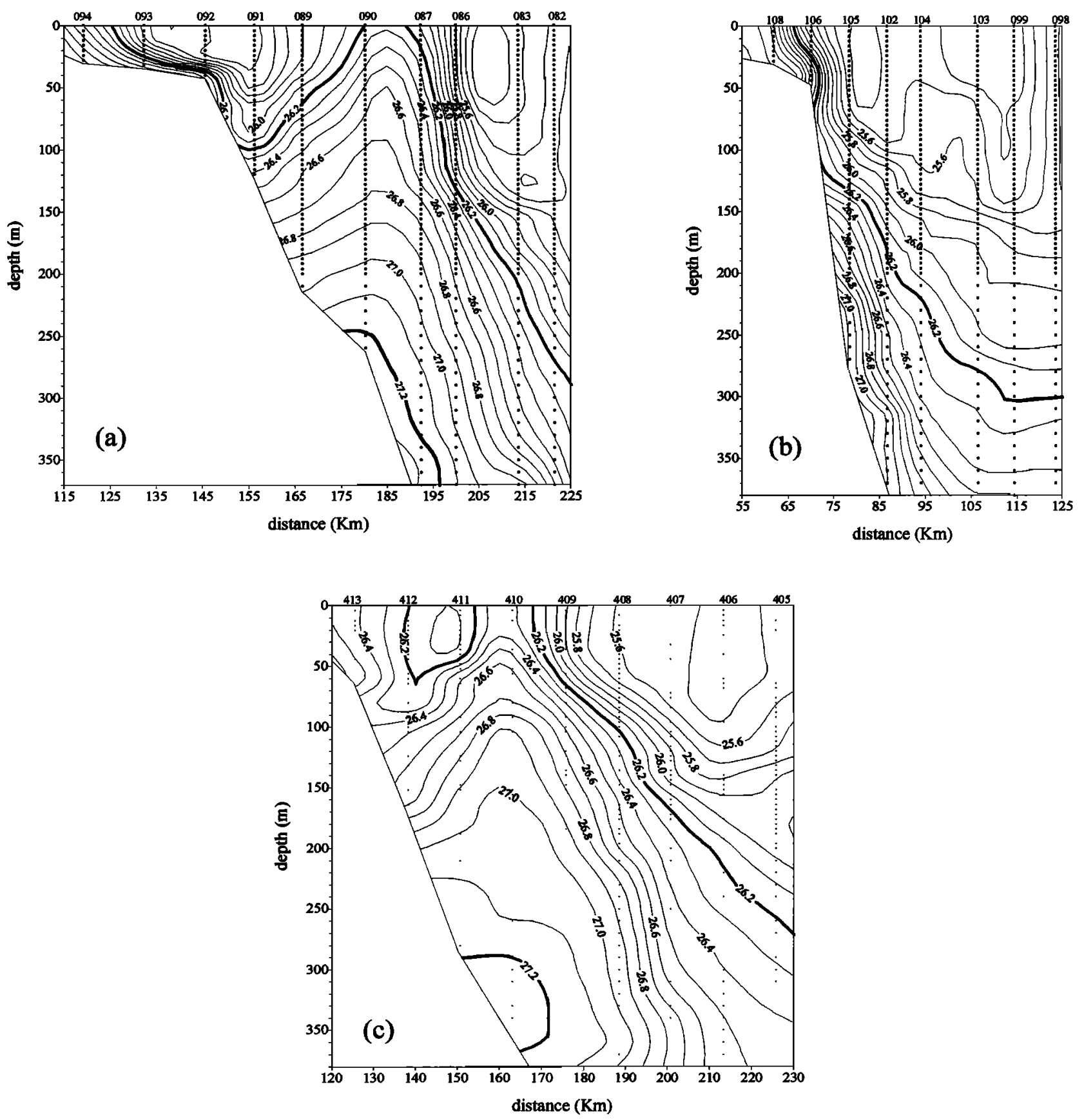

Figure 12. Potential density $\sigma_{\theta}$ distribution on (a) section K, February 11, (b) section I, February 11, and (c) section K, February 17 .

minimum corresponds to the cyclonic side of the meander's trough, where the diapycnal shear is several times larger $\left(1.5-2 \mathrm{~m}^{4} \mathrm{~kg}^{-1} \mathrm{~s}^{-1}\right)$ but $j$ is also $\sim 20-30$ times larger. In section I (Figure 14) the maximum diapycnal shear (almost $2 \mathrm{~m}^{4} \mathrm{~kg}^{-1} \mathrm{~s}^{-1}$ ) totally overlies some of the smallest separation indexes in the cyclonic side of the meander's crest, causing an extensive area of subcritical $R i$ values. Figure 15 corresponds to the isopycnic distribution across section $\mathrm{K}$ on February 17, in the absence of large meanders. In this case the maximum diapycnal shear is $\sim 1 \mathrm{~m}^{4} \mathrm{~kg}^{-1} \mathrm{~s}^{-1}$, i.e., only half the value found at Ernie's crest. Furthermore, this shear does not show good overlapping with regions of low $j$, and the corresponding $R i$ values are nowhere subcritical.

Figures 16 and 17 present the relative errors for the diapycnal shear and the Richardson number, across section $\mathrm{K}$ on February 11, as calculated using both the error propagation and Monte Carlo methods, respectively. The errors become substantially large at some places but are relatively small in regions of low $R i$ values, where mixing takes place. Furthermore, it is clear that the Monte Carlo method provides error estimates substantially smaller than the error propagation method.

The distributions of density tendency and diapycnal 

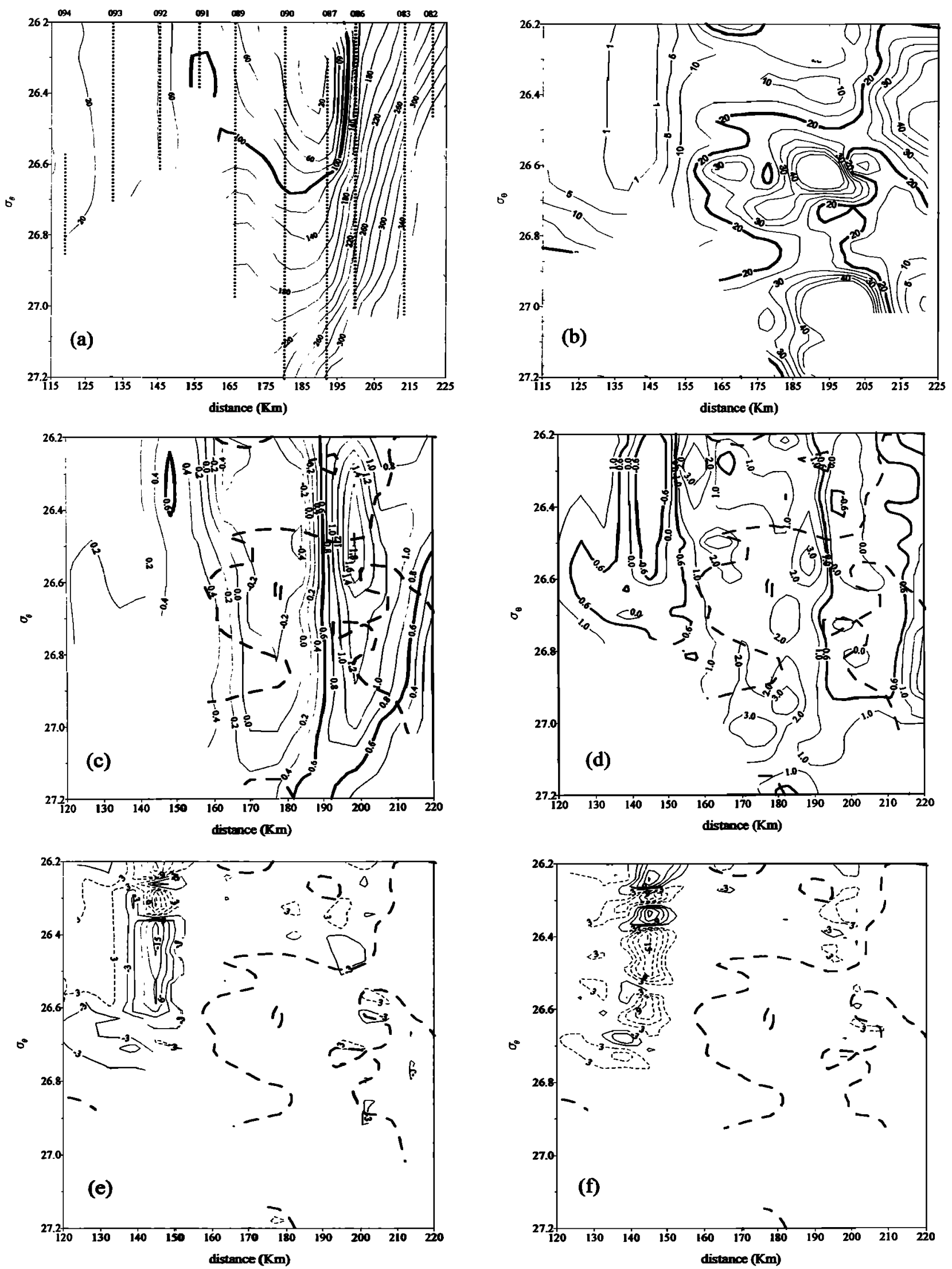

Figure 13. February 11 distribution over section $\mathrm{K}$ of (a) depth $z$, (b) separation index $j\left(10^{4}\right.$ $\mathrm{m})$, (c) diapycnal shear $\partial v / \partial \rho\left(\mathrm{m}^{4} \mathrm{~kg}^{-1} \mathrm{~s}^{-1}\right)$, the thick line corresponds to $\partial v / \partial \rho=0.6 \mathrm{~m}^{4}$ $\mathrm{kg}^{-1} \mathrm{~s}^{-1}$, (d) the logarithm of the Richardson number log $R i$, the thick line corresponds to log $R i=0.6(R i=4)$ and to $\log R i=-0.6(R i=0.25)$, (e) the logarithm of density tendency $w_{\rho}$ (units are such that $\log w_{\rho}=n$ means $w_{\rho}=\operatorname{sgn}(n) 10^{|n|-10} \mathrm{~kg} \mathrm{~m}^{-3} \mathrm{~s}^{-1}$ ), and (f) the logarithm of diapycnal convergence/divergence $\partial w_{\rho} / \partial \rho$ (units are such that $\log \left(\partial w_{\rho} / \partial \rho\right)=n$ means $\partial w_{\rho} / \partial \rho=\operatorname{sgn}(n) 10^{|n|-8} \mathrm{~s}^{-1}$ ). In Figures $13 \mathrm{c}, 13 \mathrm{~d}, 13 \mathrm{e}$, and $13 \mathrm{f}$ the $j=20 \times 10^{4} \mathrm{~m}$ isoline is plotted as a thick broken line. 

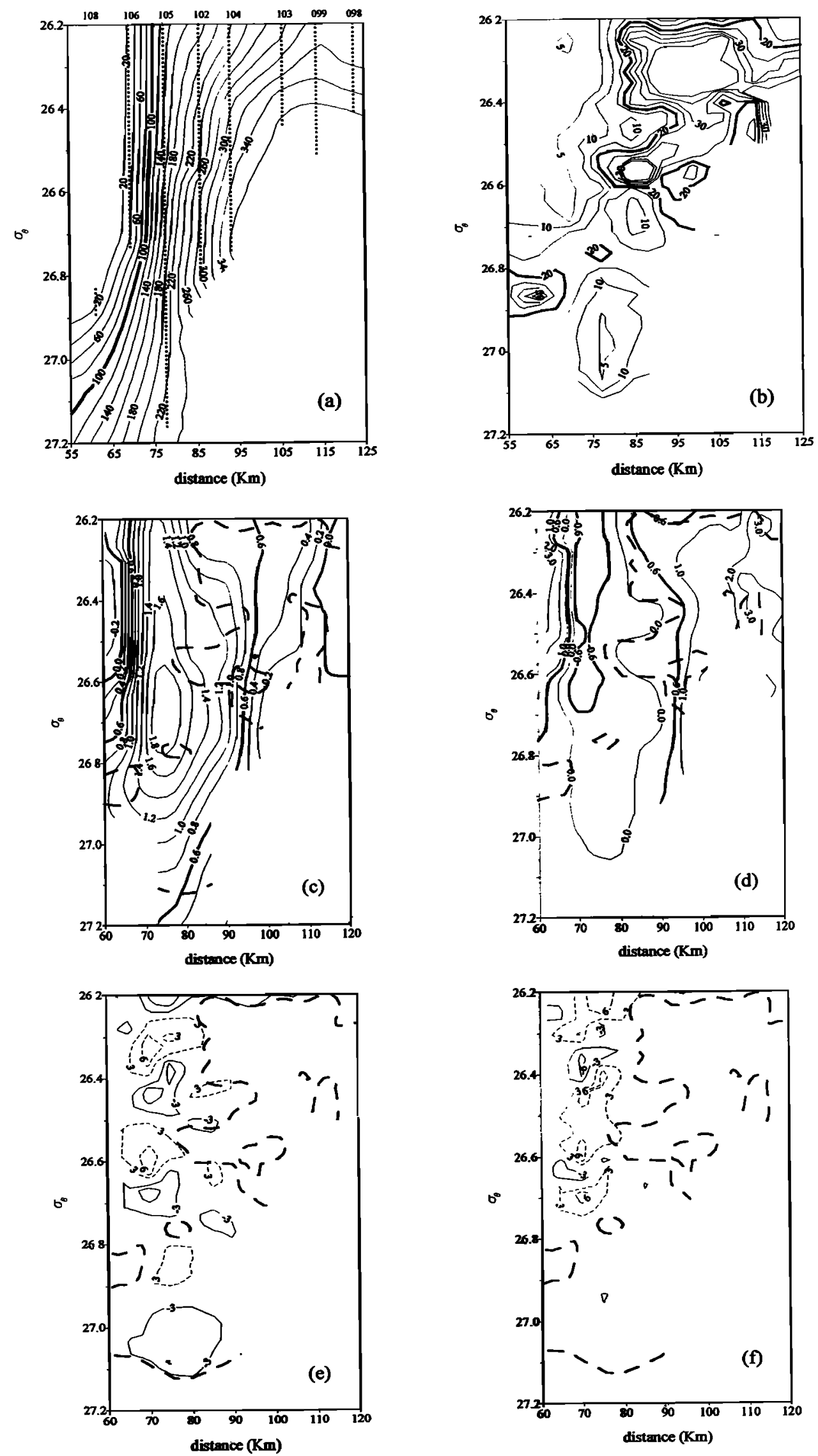

Figure 14. As in Figure 13 but for February 11, section I. 

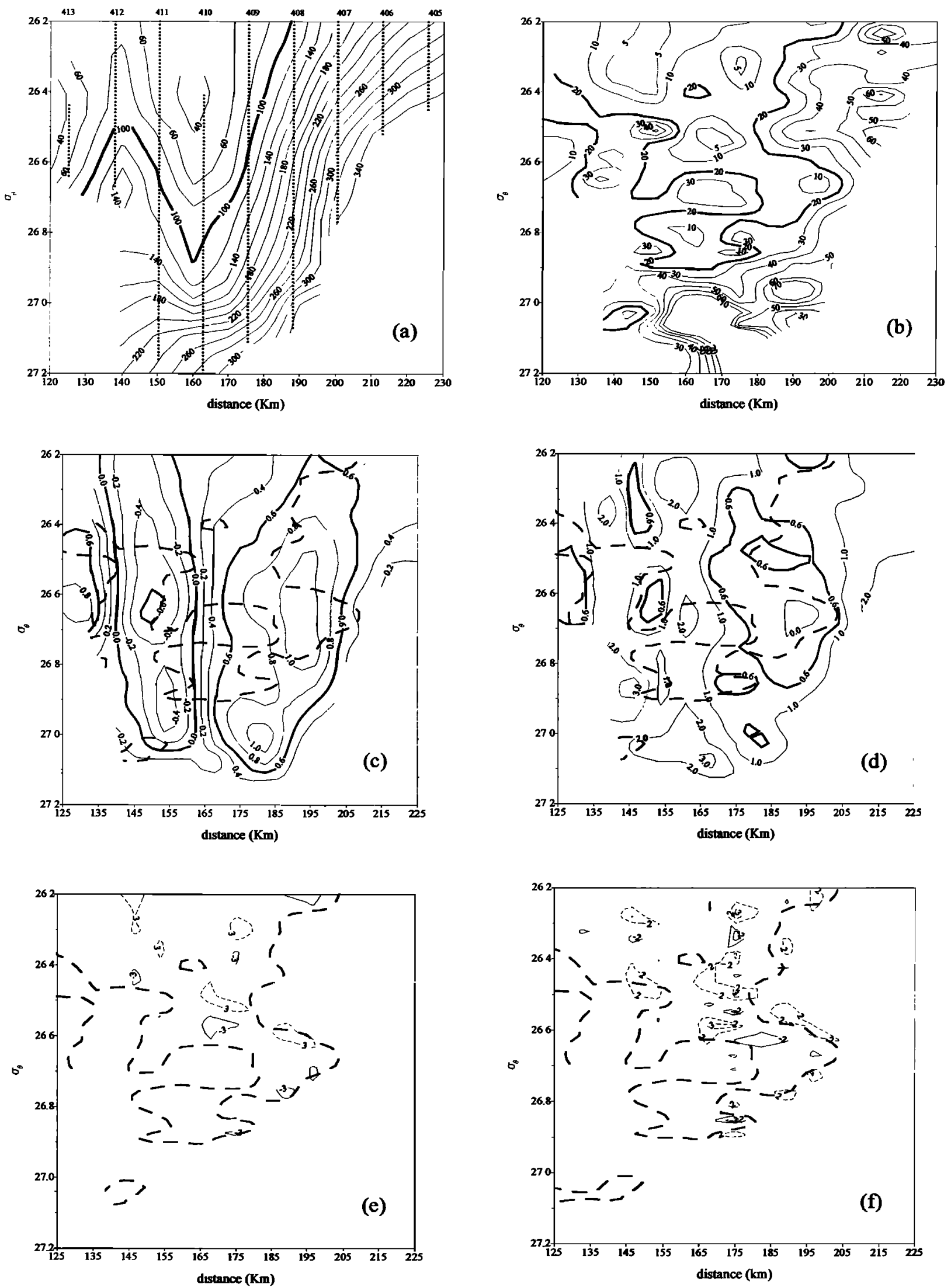

Figure 15. As in Figure 13 but for February 17, section K. 

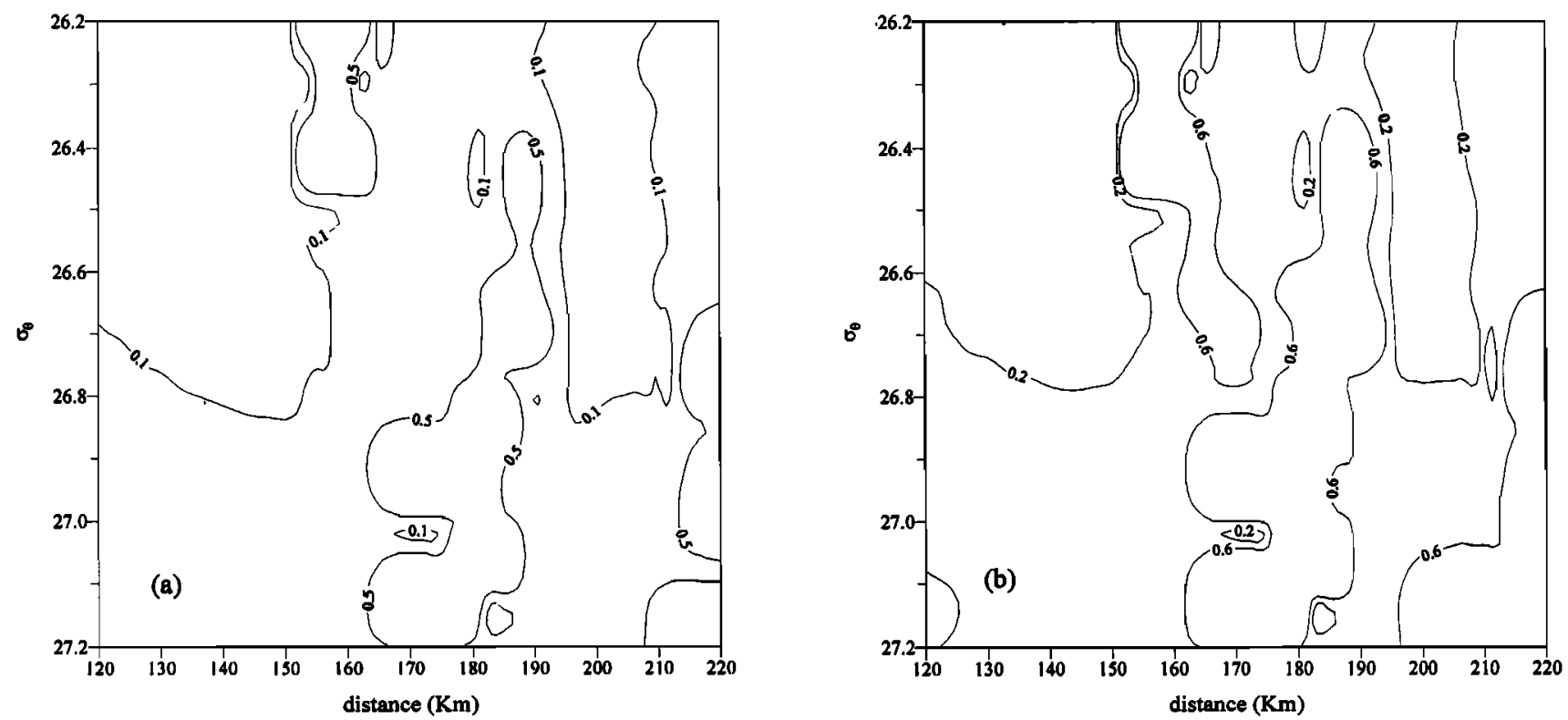

Figure 16. February 11 distribution over section $\mathrm{K}$ of (a) maximum relative error in the diapycnal shear $\delta s / s$ and (b) maximum relative error in the Richardson number $\delta R i / R i$.

convergence respond, as indicated by (3) and (7), to the distributions of $R i$ and $j$. In general, small $R i$ and $j$ values will guarantee large diapycnal mixing. Maximum activity corresponds to the closely packed filament and to the cyclonic side of the meander's crest (Figures 13 and 14). In the absence of large meanders the diapycnal mixing indicators attain much smaller values (Figure 15). A striking characteristic is the patchy character of the density tendency, with alternating positive and negative values (downward and upward diapycnal mass fluxes, respectively). The existence of several maxima (and/or minima) in density tendency causes the presence of patchy diapycnal convergence (negative values) and divergence (positive values).

\section{Conclusions}

Our calculations support the hypothesis of intense mixing in the surface and upper thermocline layers of the Gulf Stream, associated with frontogenetical stages taking place during meanders. During the passage of these meanders the maximum diapycnal shear $(\partial v / \partial \rho)$
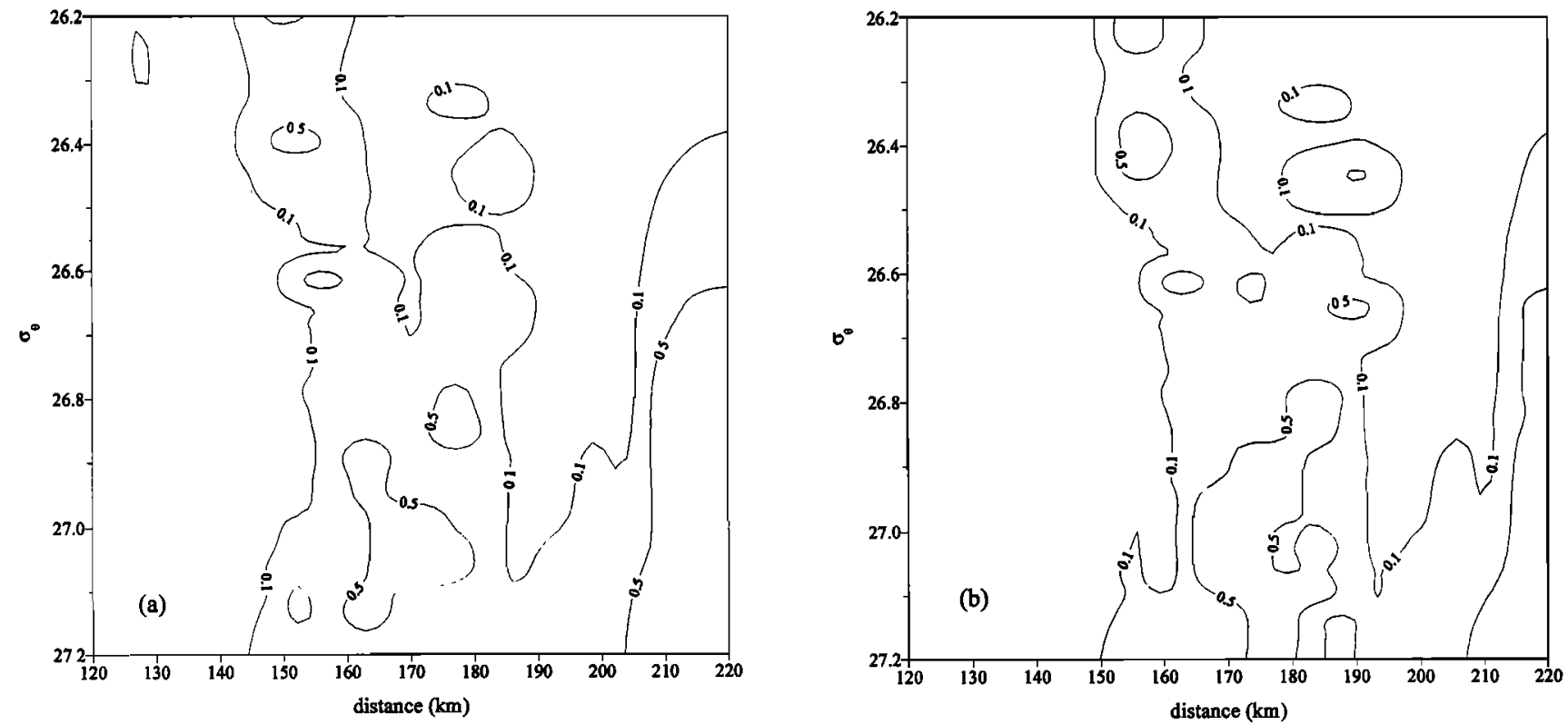

Figure 17. February 11 distribution over section $\mathrm{K}$ of (a) relative error in the diapycnal shear $\delta s / s$ as obtained using the Monte Carlo method and (b) relative error in the Richardson number $\delta R i / R i$ as obtained using the Monte Carlo method. 
shows a substantial increase as compared with situations with little meander activity. Furthermore, near the crest of the meanders the increase of diapycnal shear takes place in highly compressed regions (in Cartesian coordinates this would correspond to very high vertical shear), which causes these statically very stable regions to actually be dynamically unstable, characterized by near-critical and subcritical $R i$ numbers and large density tendencies and diapycnal convergence/divergence.

The presence of broad regions of low $R i$ values is probably related to the frontogenetical character of Gulf Stream meanders, which intensifies both the vertical stratification and the slope of the isopycnals (proportional to the diapycnal shear). This condition presumably also takes place in other unstable jets, such as the coastal upwelling jet, and may be the reason why in these systems the presence of near-critical $R i$ values is the rule rather than the exception [Kundu and Beardsley, 1991]. Our study has been limited to the production of shear-induced instabilities and mixing by the geostrophic flow field. The contribution to mixing by other sources, such as baroclinic tides and internal waves, may also be important but is beyond our scope.

Two points to note are, first, that the density tendency is directly related to the common entrainment equation through the Jacobian $(\partial z / \partial \rho)$ but differs from the vertical epipycnal velocity which may be calculated from a dynamical meteorological tendency equation. Second, while it is true that we could have used the vertical coordinate system rather than the isopycnic coordinate system, we firmly believe that isopycnic thinking has some important conceptual and practical advantages. The main conceptual benefit is that it allows us to differentiate clearly between epipycnal and diapycnal mixing, two different physical processes, instead of simply comparing vertical and horizontal mixing. Some practical advantages are that we directly obtain estimates of density changes (the natural quantity to consider when discussing mixing) and diapycnal convergence/divergence (it is this quantity and not vertical convergence/divergence that controls the rate of separation of adjacent isopycnals).

The main limitation in our results comes from the intermittent and patchy character of the mixing processes, which requires very good temporal-spatial resolution and coverage. This character is probably associated with two factors: (1) frontogenesis taking place during the passage of meanders and (2) secondary frontogenesis being produced at the edges of the original mixing region. The data set we have used is probably adequate to deal with the vertical resolution but only marginally satisfactory to provide a good picture of the horizontal structure and temporal evolution of mixing. Another limitation arises from the accuracy of the AXBT data. Our results, however, clearly suggest that shear-induced diapycnal mixing is a principal process within Gulf Stream meanders.

As part of this study and motivated by some remarks from our reviewers, we have done a careful error analysis of the variables inferred from the AXBT data. A detailed discussion and application of two methods is presented in the paper: an error propagation method, which leads to the maximum possible errors resulting from cumulative errors in the analysis, and a Monte Carlo-type method, which generates an additional number of data sets that allow the computation of the standard deviations of the inferred values.

Acknowledgments. We would like to thank John Bane for kindly providing the AXBT data (obtained with funding from the Office of Naval Research and the National Science Foundation) and for a number of comments regarding the AXBT accuracy. We are also thankful to Larry Atkinson for gently providing the Blake Plateau CTD data (obtained with funding from the Minerals Management Service) and to our two reviewers for a number of very helpful comments. This work has been supported by the Spanish government through CICYT's project FRENTES (AMB95-0731) and by the European Union through MAST-3 project CANIGO (MAS3-CT96-0060).

\section{References}

Armi, L., and N. A. Bray, A standard analytic curve of potential temperature versus salinity for the western North Atlantic, J. Phys. Oceanogr., 12, 384-387, 1982.

Atkinson, L. P., Distribution of Antarctic Intermediate Water over the Blake Plateau, J. Geophys. Res., 88, 4699$4704,1983$.

Bane, J. M., and M. H. Sessions, A field performance test of the Sippican deep aircraft-deployed expendable bathy thermograph, J. Geophys. Res., 89, 3615-3621, 1984.

Bane, J. M., Jr. , D. A. Brooks, and K. R. Lorenson, Synoptic observations of the three-dimensional structure and propagation of Gulf Stream meanders along the Carolina continental margin, J. Geophys. Res., 86, 6411-6425, 1981.

Bower, A. S., Potential vorticity balances and horizontal divergence along particle trajectories in Gulf Stream meanders east of Cape Hatteras, J. Phys. Oceanogr., 19, 1669$1681,1989$.

Bower, A. S., and T. Rossby, Evidence of cross-frontal exchange processes in the Gulf Stream based on isopycnal RAFOS float data, J. Phys. Oceanogr., 19, 1177-1190, 1989.

Boyd, J. D., Improved depth and temperature conversion equations for Sippican AXBTs, J. Atmos. Oceanic Technol., 4, 545-551, 1987.

Boyd, J. D., and R. S. Linzell, Evaluation of the Sparton tight-tolerance AXBT, J. Atmos. Oceanic Technol., 10, 892-899, 1993.

Bower, S. A., H. T. Rossby, and J. L. Lillibridge, The Gulf Stream: Barrier or blender? J. Phys. Oceanogr., 15, 24$32,1985$.

Brooks, D. A., and J. M. Bane Jr., Gulf Stream fluctuations and meanders over the Onslow Bay upper continental slope, J. Phys. Oceanogr., 11, 247-256, 1981.

Brooks, D. A., and J. M. Bane Jr., Gulf Stream meanders off North Carolina during Winter and Summer 1979, J. Geophys. Res., 88, 4633-4650, 1983.

Bryden, H. L., New polynomials for thermal expansion, adiabatic temperature gradient and potential temperature of sea water, Deep Sea Res. Oceanogr. Abstr., 20, 401-408, 1973.

Chew, F., J. M. Bane Jr., and D. A. Brooks, On vertical motion, divergence, and the thermal wind balance in colddome meanders, a diagnostic study, J. Geophys. Res., 90, 3173-3183, 1985.

Churchill, J. H., E. R. Levine, D. N. Connors, and P. C. Cornillon, Mixing of shelf, slope and Gulf Stream water over the continental slope of the Middle Atlantic Bight, Deep Sea Res., Part I, 40, 1063-1085, 1993. 
Csanady, G. T,. and P. Hamilton, Circulation of slopewater, Cont. Shelf Res., 8, 565-624, 1988.

Fisher, A., Entrainment of shelf water by the Gulf Stream northeast of Cape Hatteras, J. Geophys. Res., 77, 32483255, 1972.

Gregg, M. C., and T. B. Sanford, Signatures of mixing from the Bermuda Slope, the Sargasso Sea and the Gulf Stream, J. Phys. Oceanogr., 10, 105-127, 1980.

Hammersley, J. M., and D. C. Handscomb, Monte Carlo Methods, Monogr. Stat. Appl. Probab., Chapman and Hall, New York, 1964.

Hitchcock, G. L., T. Rossby, J. L. Lillibridge, E. J. Lessard, E. R. Levine, D. N. Connors, K. Y. Borsheim, and M. Mork, Signatures of stirring and mixing near the Gulf Stream front, J. Mar. Res., 52, 797-836, 1994.

Hood, C. A., and J. M. Bane Jr., Subsurface energetics in the Gulf Stream cyclonic frontal zone off Onslow Bay, North Carolina, J. Geophys. Res, 88, 4651-4662, 1983.

Iselin, C.O'D., Some common characteristics of the Gulf Stream and the atmospheric jet stream, Trans. N. Y. Acad. Sci., Ser. II, 13, 84-86, 1950.

Johns, E., D. R. Watts, and H. T. Rossby, A test of geostrophy in the Gulf Stream, J. Geophys. Res., 94, 3211-3222, 1989.

Keyser, D., and M. A. Shapiro, A review of the structure and dynamics of upper-level frontal zones, Mon. Weather Rev., 114, 452-499, 1986.

Kundu, P. K., and R. C. Beardsley, Evidence of a critical Richardson number in moored measurements during the upwelling season off northern California, J. Geophys. Res., 96, 4855-4868, 1991.

Lancaster, P., and K. Salkauskas, Curve and Surface Fitting (An Introduction), Academic, San Diego, 1986.

Ledwell, J. R., A. J. Watson, and C. S. Law, Evidence for slow mixing across the pycnocline from an open-ocean tracer-release experiment, Nature, 364, 701-703, 1993.

Lillibridge, J. L., G. Hitchcock, T. Rossby, E. Lessard, M. Mork, and L. Golmen, Entrainment and mixing of shelf/slope waters in the near-surface Gulf Stream, $J$. Geophys. Res., 95, 13,065-13,087, 1990.

Lohrenz, S. E., J. J. Cullen, D. A. Phinney, D. B. Olson, and C S. Yentsch, Distributions of pigments and primary production in a Gulf Stream meander, J. Geophys. Res., 98, 14,545-14,560, 1993.

Luther, M. A., and J. M. Bane Jr., Mixed instabilities in the Gulf Stream over the continental slope, J. Phys. Oceanogr., 15, 3-23, 1985.

Miller, J. L., and D. L. Evans, Density and velocity fine structure enhancement in oceanic eddies, J. Geophys. Res., 90, 4793-4806, 1985.

Munk, W. H., and E. R. Anderson, Notes on a theory of the thermocline, J. Mar. Res., 7, 276-295, 1948.

Newton, C. W., Synoptic comparison of jet stream and Gulf Stream systems, in The Atmosphere and the Sea in Motion, edited by B. Bolin, pp. 288-304, Rockefeller Inst. Press, New York, 1959.

Newton, C. W., Estimates of vertical motions and meridional heat exchange in Gulf Stream eddies and a comparison with atmospheric disturbances, J. Geophys. Res., 66, 853-870, 1961.

Newton, C. W., Fronts and wave disturbances in Gulf Stream and atmospheric jet stream, J. Geophys. Res., 83, 46974706, 1978.

Pacanowski, R. C., and S. G. H. Philander, Parameterization of vertical mixing in numerical models of tropical oceans, J. Phys. Oceanogr., 11, 1443-1451, 1981.

Padman, L., and I. S. Jones, Richardson number statistics in the seasonal thermocline, J. Phys. Oceanogr., 15, 844$854,1985$.
Palmén, E., and C. W. Newton, Atmospheric Circulation Systems, Academic, San Diego, 1969.

Park, Y., J. A. Whitehead, and A. Gnanadeskian, Turbulent mixing in stratified fluids: Layer formation and energetics, J. Fluid Mech., 279, 279-311, 1994.

Pelegrí, J. L., and G. T. Csanady, Nutrient transport and mixing in the Gulf Stream, J. Geophys. Res., 96, 25772583, 1991.

Pelegrí, J. L., and G. T. Csanady, Diapycnal mixing in western boundary currents, J. Geophys. Res., 99, 18,27518,304, 1994.

Pelegrí, J. L., and J. G. Richman, On the role of shear mixing during transient coastal upwelling, Cont. Shelf Res., 13, 1363-1400, 1993.

Pelegrí, J. L., and J. G. Richman, Correction to "On the role of shear mixing during transient coastal upwelling," Cont. Shelf Res., 14, 1645-1646, 1994.

Pelegrí, J. L., and P. Sangrà, A mechanism for layer formation in stratified geophysical flows, J. Geophys. Res., 103, 30,679-30,693, 1998.

Pelegrí, J. L., G. T. Csanady, and A. Martins, The North Atlantic nutrient stream, J. Oceanogr., 52, 275-299, 1996.

Peters, H., M. C. Gregg, and J. M. Toole, On the parameterization of equatorial turbulence, J. Geophys. Res., 93, 1199-1218, 1988.

Phillips, O. M., Turbulence in a strongly stratified fluid: Is it unstable? Deep Sea Res. Oceanogr. Abstr., 19, 7-81, 1972.

Posmentier, E. S., The generation of salinity finestructure by vertical diffusion, J. Phys. Oceanogr., 7, 298-300, 1977.

Richards, F. A., and A. C. Redfield, Oxygen-density relationships in the western North Atlantic, Deep Sea Res., 2, 182-199, 1955.

Rossby, C. G., On the vertical and horizontal concentration of momentum in air and ocean currents, Tellus, 3, 15-27, 1951.

Ruddick, B. R., and A. S. Bennett, Fine structure and mixing at the edge of a warm core ring, $J$ Geophys. Res., 90, 8943-8951, 1985.

Ruddick, B. R., T. J. McDougall, and J. S. Turner, The formation of layers in a uniformly stirred density gradient, Deep Sea Res., Part A, 36, 597-609, 1989.

Sánchez del Río, C., Análisis de Errores, Ediciones de la Univ. Complutense, Madrid, 1989.

Schmitt, R. W., R. G. Lueck, and T. M. Joyce, Fine- and microstructure at the edge of a warm-core ring, Deep Sea Res., Part A, 33, 1665-1689, 1986.

Sessions, M. H., T. P. Barnett, and W. S. Wilson, The Airborne Expendable Bathythermograph, Deep Sea Res. Oceanogr. Abstr., 23, 779-782, 1976.

Stommel, H., The Gulf Stream: A Physical and Dynamical Description, 2nd ed., 248 pp., Univ. of Calif. Press, Berkeley, 1965.

Turner, J. S., Turbulent entrainment: The development of the entrainment assumption and its application to geophysical flows, J. Fluid Mech., 173, 431-471, 1986.

Ueda, H., S. Mitsumoto, and S. Komori, Buoyancy effects on the turbulent transport processes in the lower atmosphere, Q. J. R. Meteorol. Soc., 107, 561-578, 1981.

A. Marrero-Díaz, J. L. Pelegrí, A. Rodríguez-Santana, and P. Sangrà, Departamento de Física, Facultad de Ciencias del Mar, Universidad de Las Palmas de Gran Canaria, 35017 Las Palmas de Gran Canaria, Canary Islands, Spain. (e-mail: angel.rodriguez@fisica.ulpgc.es)

(Received February 13, 1996; revised May 28, 1999; accepted June 22, 1999.) 